\title{
Evaluating the Effective Inflow Layer of Simulated Supercell Updrafts
}

\author{
CHRISTOPHER J. NOWOTARSKI \\ Department of Atmospheric Sciences, Texas A\&M University, College Station, Texas \\ John M. Peters AND JaKe P. Mulholland \\ Meteorology Department, Naval Postgraduate School, Monterey, California
}

(Manuscript received 15 January 2020, in final form 11 June 2020)

\begin{abstract}
Proper prediction of the inflow layer of deep convective storms is critical for understanding their potential updraft properties and likelihood of producing severe weather. In this study, an existing forecast metric known as the effective inflow layer (EIL) is evaluated with an emphasis on its performance for supercell thunderstorms, where both buoyancy and dynamic pressure accelerations are common. A total of 15 idealized simulations with a range of realistic base states are performed. Using an array of passive fluid tracers initialized at various vertical levels, the proportion of simulated updraft core air originating from the EIL is determined. Results suggest that the EIL metric performs well in forecasting peak updraft origin height, particularly for supercell updrafts. Moreover, the EIL metric displays consistent skill across a range of updraft core definitions. The EIL has a tendency to perform better as convective available potential energy, deeplayer shear, and EIL depth are increased in the near-storm environment. Modifications to further constrain the EIL based on the most-unstable parcel height or storm-relative flow may lead to marginal improvements for the most stringent updraft core definitions. Finally, effects of the near-storm environment on low-level and peak updraft forcing and intensity are discussed.
\end{abstract}

\section{Introduction}

The properties of the air within the inflow to supercell updrafts strongly influence vertical accelerations, vertical velocities, and consequently the ability of an updraft to produce severe weather and flash flooding. Soundingderived parameters from the near-storm environment have long been used to predict various attributes of the inflow to a storm (e.g., Showalter and Fulks 1943; Fawbush and Miller 1954; Beebe 1958; Maddox 1976; Kerr and Darkow 1996; Rasmussen and Blanchard 1998; Thompson et al. 2003; Davies 2004). Most of these parameters use the thermodynamic characteristics of a level or layer from a sounding that is assumed to be representative of the inflow layer to calculate convective available potential energy (CAPE) and convective inhibition (CIN), and relate these CAPE and CIN calculations to the potential for a convective updraft and the peak strength of an updraft if it were to form. The simplest method is a surface-based parcel, where the temperature and dewpoint are taken

Corresponding author: C. Nowotarski, cjnowotarski@tamu.edu from a surface observation (or lowest model grid level). Slightly more complicated mixed-layer or mostunstable parcel methods recognize that deep convective updrafts ingest air originating from a deeper layer, and that the characteristics at the surface are often unrepresentative of that layer. Such methods emphasize the effects of buoyancy on updraft intensity, neglecting the potential contributions of vertical perturbation pressure gradient forces (VPPGFs) to vertical velocity, particularly in supercells (e.g., Rotunno and Klemp 1982, 1985; Weisman and Rotunno 2000). In the context of mesoscale convective systems (MCSs), where the presence of a strong cold pool is integral to the self-organization of convection through forced lifting of inflow air, recent studies have developed and evaluated layer-lifting indices that incorporate the interaction between cold pools and ambient lower-tropospheric shear in determining the potential buoyancy of inflow in deep convection (e.g., Alfaro and Khairoutdinov 2015; Alfaro 2017; Alfaro and Coniglio 2018).

In response to the limitations of arbitrary, fixed estimations of the inflow layer, Thompson et al. (2007, hereafter T07) developed a method for more precisely 
determining what they refer to as the effective inflow layer (EIL; herein EIL refers specifically to the T07 parameter or our alterations to it) to a storm. This parameter was formulated based on their stated assumption that "only lifted parcels associated with CAPE will sustain a deep thunderstorm updraft, whereas parcels associated with very large CIN and/or negligible CAPE will ultimately result in storm demise." Using a database of 835 Rapid Update Cycle (RUC) proximity soundings, T07 tested several combinations of CAPE and CIN thresholds to define the EIL, concluding that the definition that resulted in a nonzero EIL depth in the largest number of cases (i.e., 95\%) was most desirable. They settled on the following definition that is widely used today: the contiguous layer wherein lifted parcels would have at least $100 \mathrm{~J} \mathrm{~kg}^{-1}$ of CAPE and CIN $<-250 \mathrm{~J} \mathrm{~kg}^{-1}$. More stringent thresholds of CAPE and CIN led to a nonzero EIL depth in a fewer number of cases, and these alternate criteria were thus discarded. Population EIL depths were relatively consistent (median values between 1400 and $1800 \mathrm{~m}$ ) between supercells and nonsupercell environments, but T07 identified a slight preference toward deeper EILs for significantly tornadic supercells over nonsupercellular convection.

Bunkers et al. (2002) highlight the importance of choosing a representative level or layer in computing both CAPE and shear for convective storms forecasting. Thus, it is not surprising that parameters using the EIL or integrated over the depth of the EIL have been developed to provide insight into the characteristics or potential severity of deep convection. Sounding-derived measures of vertical wind shear or storm-relative helicity (SRH) are generally relied on to predict convective organization and rotation, with the implicit assumption that greater organization and rotation may increase updraft strength through contributions from VPPGFs. T07 improved on fixed layer (e.g., $0-1$ or $0-3 \mathrm{~km}$ ) SRH by integrating SRH over the depth of the EIL, showing that the effective storm relative helicity (ESRH) more clearly discriminated between significantly tornadic and nontornadic supercells. T07 also showed that using the effective bulk wind difference as a measure of deep-layer shear better discriminated between tornadic and nontornadic supercells than the $0-6-\mathrm{km}$ bulk wind difference. In recognition of these improvements, EIL-derived parameters have been included in updated versions of the supercell composite parameter and significant tornado parameter as well as numerous other studies, sounding-derived parameters, and prediction systems (e.g., Smith et al. 2012; Cintineo et al. 2014; Bunkers et al. 2014; Sherburn and Parker 2014;
Davenport and Parker 2015; Van Den Broeke 2016; Hart and Cohen 2016; Gallo et al. 2018). Indeed, commonly used sounding analysis software such as the Sounding and Hodograph Analysis and Research Program in Python [SHARPPy; Blumberg et al. (2017)] now include numerous EIL-based parameters, including CAPE based on an EIL-averaged parcel. Despite the increasing ubiquity of EIL-based parameters, uncertainty remains as to its best applications. For instance, Coffer et al. (2019) show shallow-layer (500 m) SRH better discriminates between tornadic and nontornadic supercells than ESRH, but ESRH or other EIL-derived parameters may still be useful in convective hazards more directly related to peak updraft strength (e.g., hail, flash flooding, and lightning).

The assumption underlying the T07 approach to defining the inflow layer recognizes the primary importance of buoyancy in dictating updraft strength in deep convection. However, this approach implicitly allows for the potential for VPPGFs in low-level updrafts, as parcels with $-250-0 \mathrm{~J} \mathrm{~kg}^{-1}$ of CIN require a force other than buoyancy to lift them to their levels of free convection (LFC). Indeed Nowotarski et al. (2011), found that in simulations of supercells with EIL bases above the surface, midlevel supercell updrafts contained parcels originating from within shallow nearsurface stable layers. Within the T07 study only 55 of the 835 total supercells featured an EIL base above the surface. Because of this small sample size of potentially elevated storms relative to surface-based storms, it is comparatively less clear how relevant the EIL definition is for elevated storms. Given the exclusive dependence of the EIL parameter on buoyancy, it also seems reasonable to contemplate how well the EIL approximates the true inflow layer of supercell thunderstorms that often feature particularly strong lowlevel VPPGFs - particularly in situations where storms may be elevated over a surface-based layer of stable air. For instance, there is the possibility that layers not meeting the EIL criteria actively participate in updrafts given strong dynamic lifting. Alternatively, some parcels that meet the EIL criteria, but do not experience adequate upward VPPGFs may not overcome their CIN and participate in the updraft above their LFC. In the latter possibility, vertical wind shear and SRH metrics that depend on the EIL may be overestimated such that storm severity is over predicted. Finally, air entrained from above the EIL may obtain adequate buoyancy through mixing such that it participates in the updraft core.

The uncertainties described above motivate a verification study of the EIL, particularly for situations where elevated supercells are likely. This could better inform 
the use of EIL-derived parameters as forecasting tools. While an observation-based verification would be ideal, the lack of direct observations and limitations of dual-Doppler datasets in determining updraft parcel trajectories with adequate detail prevent a robust verification in a range of environments. Thus, we turn to numerical simulations of supercell and nonsupercell convection in a variety of real kinematic and thermodynamic environments to test the performance of the EIL parameter. Specifically, we address the following research questions:

1) How accurate is the EIL formulation of T07 in predicting the origin heights of air in supercell and nonsupercell updrafts cores?

2) How does the EIL performance vary as the definition of updraft core is changed?

3) Which environmental parameters best predict EIL performance, and more broadly, low-level and peak updraft forcing and intensity in real environments?

and the corresponding hypotheses:

1) The EIL definition is more accurate in the case of supercells than in the case of nonsupercells because of the comparatively large midtropospheric entrainment rates in the case of nonsupercells (e.g., Peters et al. 2019, 2020b).

2) The probability of detection of the updraft core composition by the EIL increases with the magnitude of the vertical velocity threshold used to define the updraft core.

3) The EIL probability of detection improves as environmental parameters related to updraft intensity, such as CAPE and vertical wind shear, increase.

\section{Methods}

\section{a. Simulation base-state selection}

To answer our research questions, a series of 15 idealized, horizontally homogeneous numerical simulations were performed using CM1 version 19.8 (Bryan and Fritsch 2002). To assess the EIL over a range of supercell and nonsupercell storm environments, we used the T07 database of RUC proximity soundings. Our goal was to generate an archetypal base-state temperature and wind profile for the significantly tornadic supercell (ST), weakly tornadic supercell (WT), nontornadic supercell (NT), and nonsupercell (NS) storm types included in the T07 database. Rather than randomly selecting soundings of each storm type, we first classified the database using the four-variable (temperature, dewpoint temperature, $u$-wind component, $v$-wind component) self-organizing map (SOM) method described by Nowotarski and Jones (2018). A 16-node SOM, considering vertical profiles of all four variables derived from all RUC proximity soundings in the database, including nonsupercell storms was constructed, and we calculated the percent of each storm type matching each resulting node.

Our initial plan was to use the average vertical profile of all storms (regardless of type) matching the node with the highest percentage of each storm type (relative to other storm types within that node) to represent that storm type in our range of simulation base states. However, the node-averaged soundings generally did not result in sustained deep convection in our simulations. We attribute this failure to considerable low- to midlevel tropospheric dryness in the node averages (translucent profiles in Fig. 1) as compared with the Weisman and Klemp (1982) profile and RUC soundings that ultimately did result in sustained deep convection. Thus, we ultimately selected one RUC profile associated with each of the four storm types that matched the node where that storm type was most common. For instance, for our ST sounding, we selected an ST RUC profile that matched the node with the highest percentage of ST cases. This selection process was semirandom; however, care was taken to ensure that the characteristics of the selected profile closely matched the pattern identified by that node and that the selected profile could sustain deep convection in a simulation, even with the modifications discussed below. In practice, this led to the selection of RUC profiles that had considerably more low- to midlevel tropospheric moisture than the node averages, but similar hodograph shapes. This resulted in one base state for each storm type, which is relatively representative of the node average and other profiles matching that node except for the aforementioned moisture differences (cf. node average profiles to real-case RUC profiles in Fig. 1). In addition, we also used the analytic Weisman and Klemp (1982) thermodynamic and wind profiles (WK) as a base state to compare with the realistic profiles.

This process resulted in five base-state thermodynamic and kinematic soundings (Fig. 1). Despite a range of EIL depths, most-unstable parcel heights, and resulting CAPE, CIN, and shear parameters consistent with the resulting storm types, each of the unmodified base states had large surface-based CAPE (Table 1) and a surface-based EIL. This, in part, was due to the large percentage ( $93 \%$ ) of surface-based storms included in the T07 database. Thus, to fully 

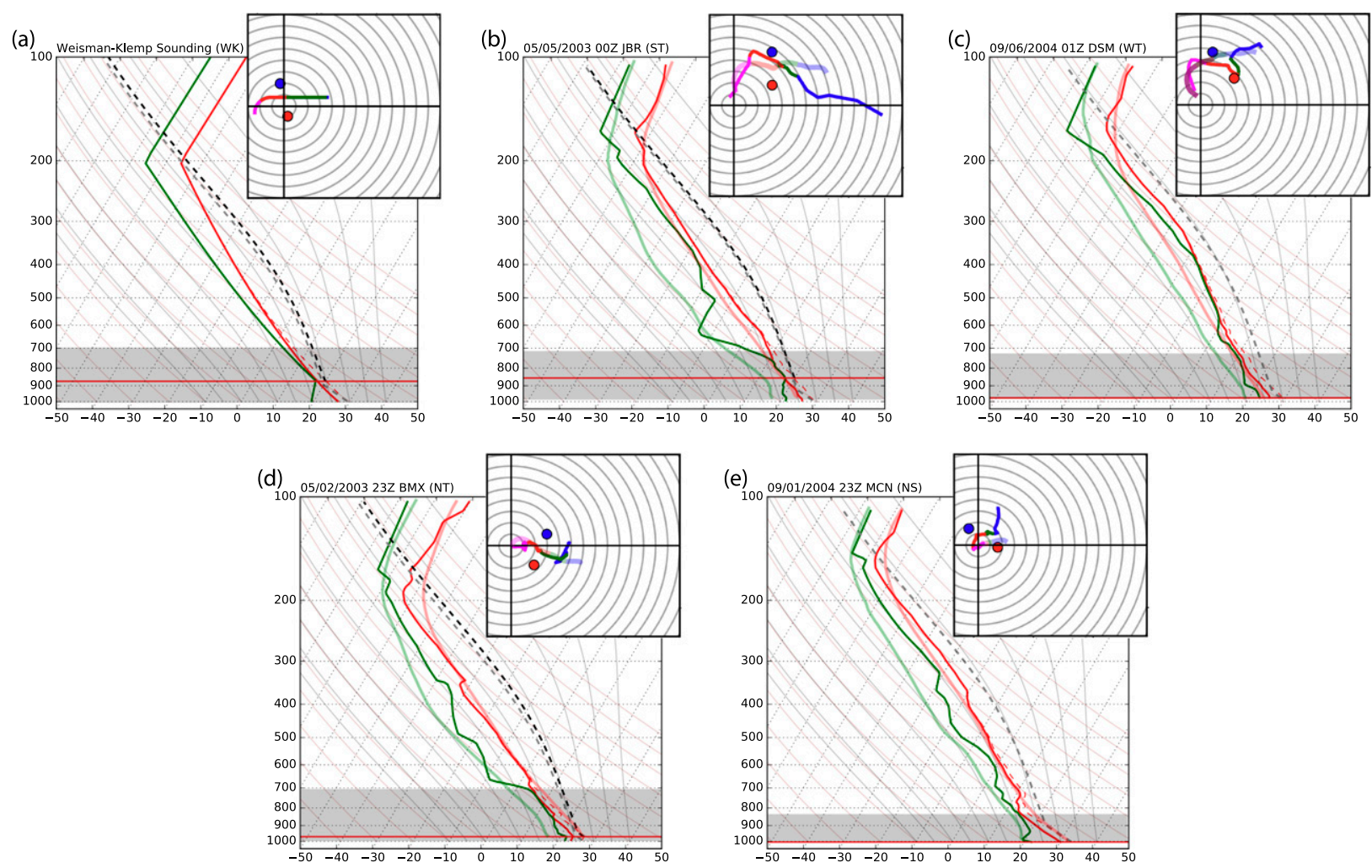

FIG. 1. Unmodified, base-state skew $T-\log p$ diagrams and hodographs for each simulation, including the Weisman and Klemp (1982) analytic profiles (WK) and RUC analysis gridpoint profiles from a significantly tornadic supercell at 0000 UTC 5 May 2003 near Jonesboro, AR (ST); a weakly tornadic supercell at 0100 UTC 6 Sep 2004 near Des Moines, IA (WT); a nontornadic supercell at 2300 UTC 2 May 2003 near Birmingham, AL (NT); and a nonsupercellular severe thunderstorm at 2300 UTC 1 Sep 2004 near Macon, GA (NS). On skew $T-\log p$ diagrams, red profiles are temperature $\left({ }^{\circ} \mathrm{C}\right)$, green profiles are dewpoint temperature $\left({ }^{\circ} \mathrm{C}\right)$, dashed red profiles are virtual temperature $\left({ }^{\circ} \mathrm{C}\right)$, thick dashed black lines are lifted most unstable parcel virtual temperature $\left({ }^{\circ} \mathrm{C}\right)$, thick dashed gray lines are lifted surface parcel virtual temperature $\left({ }^{\circ} \mathrm{C}\right)$, horizontal red lines indicate the height of the most unstable parcel, and the shaded gray layer indicates the effective inflow layer. On hodographs, winds from 0 to $1 \mathrm{~km}$ AGL are in magenta, 1-3 km AGL are red, 3-6 km AGL are green, and 6-12 km AGL are blue. Dots on the hodograph represent left (blue) and right (red) moving Bunker's storm motions and speed rings are at 10 -kt $\left(1 \mathrm{kt} \approx 0.51 \mathrm{~m} \mathrm{~s}{ }^{-1}\right)$ increments. Translucent skew $T-\log p$ and hodographs are the node-averaged profiles of the SOM node from which each real case base state is taken.

test the EIL for elevated supercells (and nonsupercells), each base-state thermodynamic profile was modified in order to stabilize the low-level environment and raise the EIL base. First, a shallow $(S)$ surface-based inversion with a temperature lapse rate of $-20^{\circ} \mathrm{C} \mathrm{km}^{-1}$ was applied over a depth of $300 \mathrm{~m}$ to each base state (Fig. 2b). Then, in a deep $(D)$ inversion set of simulations, the same lapse rate was applied over a depth of $600 \mathrm{~m}$ (Fig. 2c). To avoid supersaturation in the cases where the surface temperature modification resulted in a modified temperature below the original dewpoint temperature at that layer, the dewpoint temperature was set to $1^{\circ} \mathrm{C}$ less than the modified temperature.

Table 1 shows relevant thermodynamic and kinematic sounding-derived parameters for all 15 simulation base states. ${ }^{1}$ In general, the WK base-state characteristics fall somewhere between those of the corresponding ST and WT base states. For all storm types, the addition of the near-surface stable layers reduces or eliminates surface-based CAPE such that the EIL base raises from the surface, with the highest EIL base at $400 \mathrm{~m}$. The most-unstable (MU) parcel height ranges from

\footnotetext{
${ }^{1}$ Most sounding-derived parameters were computed using the Sounding/Hodograph Analysis and Research Program in Python [SHARPpy; Blumberg et al. (2017)], which uses the modified Bunkers right-moving storm motion (Bunkers et al. 2014). This storm motion uses a pressure-weighted mean wind with the effective inflow layer as a base. Thus, some fixed-layer, storm-relative quantities vary slightly for simulations with identical hodographs, but varied near-surface stability.
} 
TABLE 1. Sounding-derived parameters for each simulation base state. "Inf" signifies situations with infinite SBCIN (e.g., no CAPE exists for a surface-based parcel).

\begin{tabular}{|c|c|c|c|c|c|c|c|c|c|c|c|c|c|c|c|}
\hline & WK & WKS & WKD & ST & STS & STD & WT & WTS & WTD & NT & NTS & NTD & NS & NSS & NSD \\
\hline $\operatorname{SBCAPE}\left(\mathrm{J} \mathrm{kg}^{-1}\right)$ & 2274 & 48 & 0 & 2717 & 0 & 0 & 271 & 0 & 0 & 3950 & 0 & 0 & 2429 & 0 & 0 \\
\hline SBC & 42 & 520 & Inf & 48 & Inf & Inf & 17 & Inf & Inf & 25 & Inf & Inf & 0 & Inf & Inf \\
\hline $\operatorname{MUCAPE}\left(\mathrm{J} \mathrm{kg}^{-1}\right)$ & 2821 & 2821 & 2821 & 2998 & 2998 & 2998 & 2277 & 2063 & 1611 & 4681 & 3799 & 3132 & 2429 & 1680 & 1680 \\
\hline $\operatorname{MUCIN}\left(\mathrm{J} \mathrm{kg}^{-1}\right)$ & 0 & 0 & 0 & 0 & 0 & 0 & 17 & 4 & 4 & 1 & 6 & 7 & 0 & 1 & 1 \\
\hline MU parcel & 56 & 156 & 156 & 1304 & 1304 & 1304 & 0 & 303 & 500 & ותו & 297 & 508 & 0 & 601 & 601 \\
\hline EIL base & 0 & 100 & 300 & 0 & 200 & 400 & 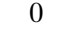 & 200 & 400 & 0 & 100 & 300 & 0 & 200 & 400 \\
\hline IL & 15 & 3150 & 3150 & 2800 & 2800 & 2800 & 2500 & 2500 & 2500 & 2900 & 2900 & 2900 & 1600 & 1600 & 1600 \\
\hline IIL & 0 & 3050 & 2850 & 2800 & 2600 & 2500 & 2500 & 2300 & 2100 & 2900 & 2800 & 2600 & 1600 & 1400 & 1200 \\
\hline ) & 61 & 61 & 61 & 58 & 58 & 58 & 41 & 41 & 41 & 44 & 44 & 44 & 18 & 18 & 18 \\
\hline$H\left(m^{2} s^{-2}\right)$ & 77 & 77 & 79 & 265 & 262 & 246 & 293 & 285 & 287 & 47 & 45 & 45 & -4 & -4 & -4 \\
\hline $0-3-\mathrm{km}$ SRH $\left(\mathrm{m}^{2} \mathrm{~s}^{-2}\right)$ & 187 & 187 & 188 & 451 & 440 & 419 & 344 & 350 & 354 & 103 & 100 & 99 & 87 & 87 & 87 \\
\hline $\begin{array}{l}\text { Effective layer } \\
\text { SRH }\left(\mathrm{m}^{2} \mathrm{~s}^{-2}\right)\end{array}$ & 195 & 187 & 171 & 444 & 372 & 247 & 340 & 199 & 149 & 102 & 72 & 60 & 23 & 7 & 9 \\
\hline 0-1-km SR Flow ( & 14.0 & 14.0 & 14.0 & 15.2 & 15.2 & 15.2 & 18.0 & 18.0 & 18.0 & 10.6 & 10.6 & 10.6 & 6. & 6.9 & 6.9 \\
\hline $0-3-\mathrm{km} \mathrm{S}$ & 11.9 & 11.9 & 11.9 & 13.8 & 13.8 & 13.8 & 9.9. & 9.9 & 9.9 & 9.5 & 9.5 & 9.5 & 5 . & 5.4 & 5.4 \\
\hline Effective layer SR flow $\left(\mathrm{m} \mathrm{s}^{-1}\right)$ & 11.7 & 11.6 & 11.5 & 14.1 & 13.9 & 13.8 & 11.3 & 10.7 & 9.9 & 9. & 9.5 & 9.6 & 7.2 & 7.4 & 7.8 \\
\hline SCP & 11.0 & 10.6 & 9.6 & 26.6 & 22.3 & 14.8 & 15.5 & 8.2 & 4.8 & 9. & 5.4 & 3.3 & 0.6 & 0 & 0 \\
\hline STP & 3.2 & 2.6 & 0.4 & 7.9 & 4.6 & 0.1 & 2.3 & 0.6 & 0 & 1.7 & 0.8 & 0.1 & 0 & 0 & 0 \\
\hline
\end{tabular}

the surface to $1304 \mathrm{~m}$, with varying positions within the EIL across simulations. Deep-layer shear (represented by the $0-6 \mathrm{~km}$ bulk wind difference) is relatively strong for all but the NS type, and SRH decreases progressively from ST to NS types. As a consequence of the reduction in the EIL thickness, ESRH decreases as the depth of the stable layer increases. Finally, both the supercell composite parameter (SCP) and the significant tornado parameter (STP) generally decrease when transitioning from ST to NS storm types and as the depth of the stable layer is increased. In summary, a reasonably wide range of base-state thermodynamic and kinematic environments supportive of supercell and nonsupercellular convection resulted from the 15 base states, including a relatively wide range of EIL bases, tops, depths and MU parcel levels relative to the EIL. Thus, the performance of the EIL can be tested over a realistic range of environments.

\section{b. Numerical model configuration}

Each of the storm environments described above serves as the horizontally homogeneous base state for a 2-h simulation. The simulations were performed on a $120 \mathrm{~km} \times 120 \mathrm{~km} \times 20 \mathrm{~km}$ domain with horizontal grid spacing of $250 \mathrm{~m}$ and a vertical grid spacing of $50 \mathrm{~m}$ below $4 \mathrm{~km}$ stretched to a grid spacing of $250 \mathrm{~m}$ above $13 \mathrm{~km}$. The upper and lower boundary conditions were rigid and free slip with Rayleigh damping applied above $15 \mathrm{~km}$ and open-radiative horizontal
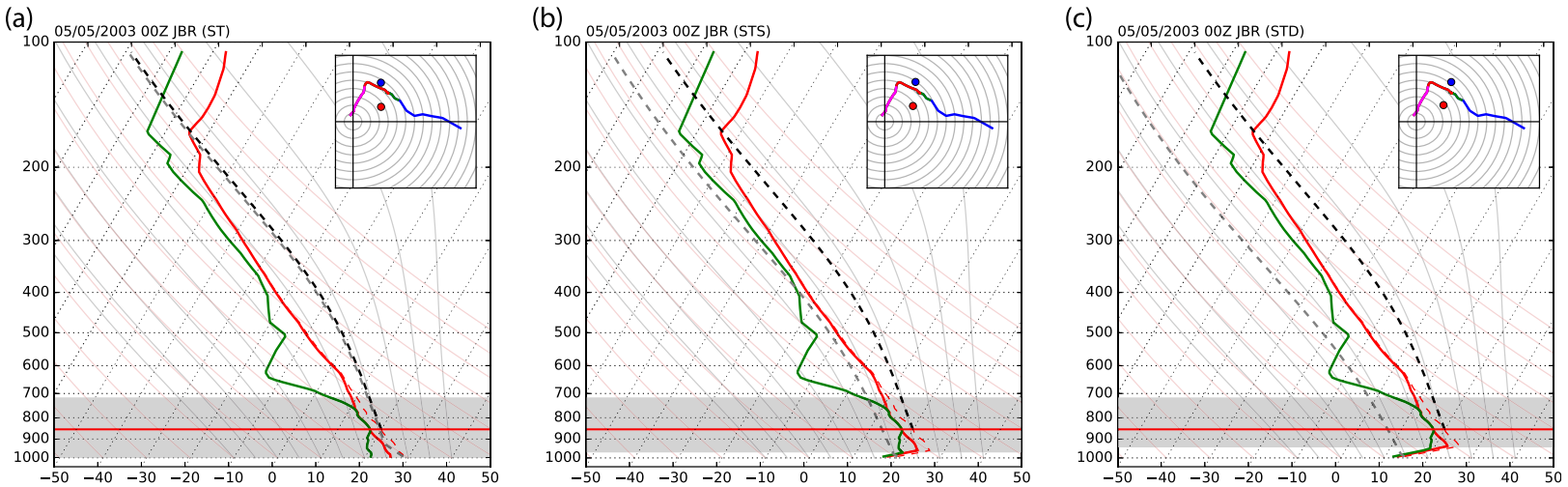

FIG. 2. As in Fig. 1, but illustrating experimental modifications to the base-state temperature and dewpoint temperature profiles using the significantly tornadic (ST) case as an example with the addition of a shallow stable layer (STS) and a deep stable layer (STD). 
boundary conditions. Simulations were performed with CM1 in the large-eddy simulation configuration with the Deardorff (1980) subgrid-scale TKE scheme, fifthorder advection, and a time-splitting pressure solver with acoustic wave terms solved on smaller time steps (Klemp and Wilhelmson 1978). The Coriolis force, radiation, and surface fluxes of heat, moisture, and momentum are omitted. Precipitation microphysics were parameterized using the NSSL two-moment scheme including both graupel and hail (Mansell et al. 2010). In each simulation, deep convection was initialized at the center of the domain using an updraft nudging technique following Naylor and Gilmore (2012). The only changes in the updraft nudging from Naylor and Gilmore (2012) were a modified vertical position $(z=1000 \mathrm{~m})$ and vertical radius $(1000 \mathrm{~m})$ of the spheroid over which the updraft forcing is applied as well as reduction of the period of forcing to the first $1200 \mathrm{~s}$ of the model integration. Grid translation was applied to each simulation based on the unique storm motion resulting from each basestate wind profile (Fig. 1) in order to keep the resulting deep convection approximately centered in the domain.

\section{c. Passive tracer method for updraft parcel origin analysis}

To track the vertical motion of air originating at various layers, each simulation was initialized with an array of passive tracers. For each 100 -m-thick layer below $5 \mathrm{~km}$ and each 500-m-thick layer above $5 \mathrm{~km}$, a unique passive tracer was defined with the initial concentration set to $100 \%$ within that layer and $0 \%$ at all heights outside that layer. Thus, the initial condition was stratified with 80 unique passive fluid tracers, which were advected by the simulation as it integrated. Consequently, at any time in the simulation, the concentration of each passive tracer at any grid point represents the amount of air at that grid point originating from the corresponding layer in the base-state. By comparing the tracer origin heights to the EIL, the proportion of air at any location in the domain originating within, below, or above the EIL can then be calculated. More specifically, if the midpoint height of the passive tracer layer was greater than or equal to the bottom height of the EIL or less than or equal to the EIL top height, that tracer was considered part of the EIL.

Next, the updraft core of each simulated supercell was identified by locating the maximum vertical velocity associated with the dominant right-moving supercell at each simulation time after $60 \mathrm{~min}$ (for the nonsupercell simulations, the strongest vertical velocity within the domain was used). A $30 \mathrm{~km} \times 30 \mathrm{~km}$ subdomain centered on each maximum updraft coordinate was defined, then for each vertical level, any grid point with vertical velocity exceeding a specified percentile of vertical velocity over $0.1 \mathrm{~m} \mathrm{~s}^{-1}$ was classified as part of the updraft core at that level. By comparing concentrations of tracers from each level at these grid points for various updraft percentile thresholds used to define the updraft core and any height within the updraft, we can determine the accuracy of the T07 EIL definition in predicting the composition of the updraft core at that level. For most subsequent analysis, passive tracer (i.e., updraft origin level) concentrations were averaged over the $60-90$-min period of each simulation. $^{2}$

\section{d. Calculation of vertical perturbation pressure gradient forcing terms}

In addition to buoyancy, vertical accelerations due to vertically oriented dynamic perturbation pressure gradients (DPA) have been shown to enhance supercell updrafts (e.g., Weisman and Klemp 1984; Weisman and Rotunno 2000), whereas vertical accelerations due to a vertically oriented buoyancy perturbation pressure gradient (BPA) are often downward oriented and hinder updraft intensity. These acceleration terms may be understood in terms of the anelastic vertical momentum equation:

$$
\frac{D w}{D t}=B-\frac{1}{\rho_{0}} \frac{\partial p_{B}^{\prime}}{\partial z}-\underbrace{\frac{1}{\rho_{0}} \frac{\partial p_{\mathrm{LD}}^{\prime}}{\partial z}-\frac{1}{\rho_{0}} \frac{\partial p_{\mathrm{NLD}}^{\prime}}{\partial z}}_{\mathrm{BPA}},
$$

where $B \equiv-g\left(\rho^{\prime} / \rho_{0}\right)-g q_{i}$ is buoyancy (where $q_{i}$ is the mixing ratio of the $i$ th hydrometeor species) and DPA is the sum of the vertical acceleration terms due to linear dynamic pressure perturbations (LDPA) and nonlinear dynamic pressure perturbations (NLDPA). The decomposed pressure terms in Eq. (1) are defined as follows:

$$
\begin{aligned}
\nabla^{2} p_{B}^{\prime} & =\frac{\partial\left(\rho_{0} B\right)}{\partial z}, \quad \nabla^{2} p_{\mathrm{LD}}^{\prime}=-\rho_{0} \nabla w \cdot \frac{d \mathbf{V}_{0}}{d z}, \\
\nabla^{2} p_{\mathrm{NLD}}^{\prime} & =-\nabla \cdot\left[\rho_{0}\left(\mathbf{V}^{\prime} \cdot \nabla\right) \mathbf{V}^{\prime}\right],
\end{aligned}
$$

where $\rho_{0}(z)$ is the density from the initial model sounding, $\mathbf{V}_{0}$ is the horizontal wind from the initial model sounding, $\mathbf{V}^{\prime} \equiv \mathbf{V}-\mathbf{V}_{0}$ is the storm modified wind field and $\mathbf{V}$ is the total wind field, $p_{B}^{\prime}$ is referred

\footnotetext{
${ }^{2}$ The results at any particular time during the mature phase of deep convection are qualitatively similar to the 60-90-min average results.
} 
to as "buoyancy pressure perturbation," $p_{\mathrm{NLD}}^{\prime}$ is referred to as "nonlinear dynamic pressure perturbation," and $p_{\mathrm{LD}}^{\prime}$ is referred to as "linear dynamic pressure perturbation." All pressure perturbations and their associated forcing terms were calculated using the in-line code and direct output variables now available in CM1. With open radiative boundary conditions, as set here, CM1 uses the method of images in a horizontal Fourier transform to enforce zero-gradient lateral boundary conditions.

Both DPA and BPA are also thought to be influenced by properties of the EIL. For instance, BPA is primarily dependent on updraft buoyancy, which itself results from the release of CAPE. DPA, on the other hand, is connected to complex flow interactions between the environment (including the inflow) characteristics and the updraft, which include (but are not limited to) the tilting of ambient inflow horizontal vorticity into the vertical direction and the associated dynamic pressure perturbations. In the context of supercell updrafts, DPA is often associated with the vertical distribution of vertical vorticity and attendant nonlinear dynamic negative pressure perturbation, wherein a mesocyclone may enhance updrafts below the level of maximum vertical vorticity (e.g., Rotunno and Klemp 1982, 1985; Weisman and Rotunno 2000). Because of these connections between the inflow layer, vertical accelerations, and updraft speed, it is important that we understand what background environmental and cloud-scale processes determine the extent of a storm's inflow layer.

\section{Results and discussion}

All 15 simulations employing the base states described above resulted in sustained deep convection. The unmodified supercell base states (WK, ST, WT, and NT) all resulted in a relatively steady, rightmoving cyclonic supercell with generally one large updraft and at least transient, if not permanent, reflectivity features characteristic of supercells (e.g., hook echoes, inflow notches, forward flank reflectivity cores; Figs. 3a,d,g,j). In general, as the stable layers were added to the base states, convection tended to become weaker and less obviously supercellular (cf. Figs. 3d,e,f), though the WK suite of simulations remained quite strong with well-defined supercellular characteristics. Moreover, the peak updraft cores in the WK simulations tended to be more coherent in the sense that the 95th percentile of vertical velocity was confined to one contiguous region with relatively smooth edges, particularly when compared with the WT suite of simulations (cf. Figs. 3a,g). The NS base states resulted in multicellular convection with clusters of more transient, smaller updraft cores (Fig. 3m).

\section{a. Comparison of EIL performance for varied storm types}

To address our first research question, we examine the distribution of the origins of air within the updraft core at each altitude for each simulation as compared with the sounding-derived EIL for each simulation (Fig. 4). For an updraft core threshold definition of the 95th percentile of vertical velocity exceeding $0.1 \mathrm{~m} \mathrm{~s}^{-1}$ at each height, it is clear that the vast majority of air within the updraft core above $\sim 2 \mathrm{~km}$ originates within the T07 EIL for the WK, ST, and NT sets of simulations, even when the EIL is elevated (Figs. 4a-f,j,k,l). The notable exceptions are the WT and NS classes of simulations, which generally have weaker updrafts and much lower levels of peak vertical velocity (indeed, many of these updrafts do not reach the tropopause; Figs. 4h,i,m,n,o). While much of the updraft core air in these simulations originates within the EIL, a considerable fraction originates above the EIL, which is representative of entrainment of midtropospheric air into the updraft core. It also appears that the T07 EIL may under predict depth of the true inflow layer for the NS storm types given the extension of the simulated inflow layer above the EIL top to $2 \mathrm{~km}$ (Figs. 4m,n,o).

While, at least qualitatively, the EIL appears to capture the majority of air participating in many of the updrafts, it appears to "overforecast" the inflow layer in many supercell cases, where significant portions of the T07 EIL do not participate in the updraft core (e.g., Fig. 4a). It seems that in many simulations, the true inflow layer is focused on a relatively narrow layer centered on or near the MU parcel layer (Figs. 4a-i). There is also evidence of low-level updrafts "recycling", outflow air in some simulations where low-level (below $2 \mathrm{~km}$ ) updrafts have origins extending above $4 \mathrm{~km}$ (Figs. 4b,c,j-1).

To clarify the physical features leading to differences in updraft origin distributions, Fig. 5 illustrates a stark contrast between the updraft characteristics and airflow between the nonsupercell (left column, NSD) and typical $^{3}$ supercell (right column, WKD) with a surface inversion. First, the NSD updraft is comprised of a series of discrete rising thermals with relatively weak $(w<$ $20 \mathrm{~m} \mathrm{~s}^{-1}$ ) maximum vertical velocity, whereas the WKD supercell updraft is a wide, continuous, plume of upward motion with a relatively strong $\left(w>50 \mathrm{~ms}^{-1}\right)$ peak updraft (cf. Figs. 5a,b). These results are consistent with

\footnotetext{
${ }^{3}$ The features of the WKD updraft and airflow shown here are generally representative of most of the supercell simulations.
} 

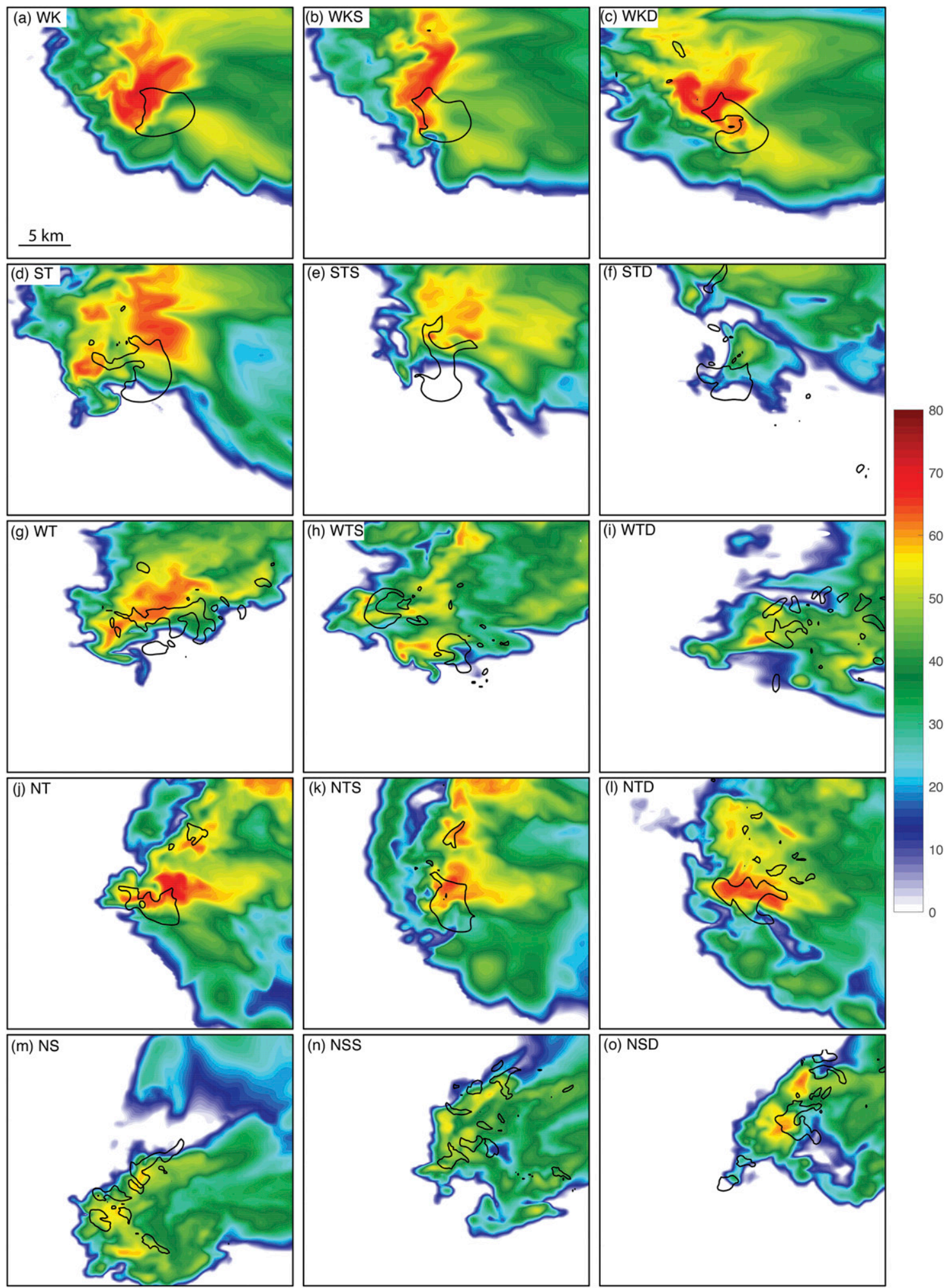

FIG. 3. Plan views of simulated reflectivity at $500 \mathrm{~m}$ above the surface with the 95 th percentile of vertical velocity at the level of peak vertical velocity contoured in black for each simulation as labeled at $60 \mathrm{~min}$ in the simulations. Cross sections are centered on the maximum updraft at any height. 


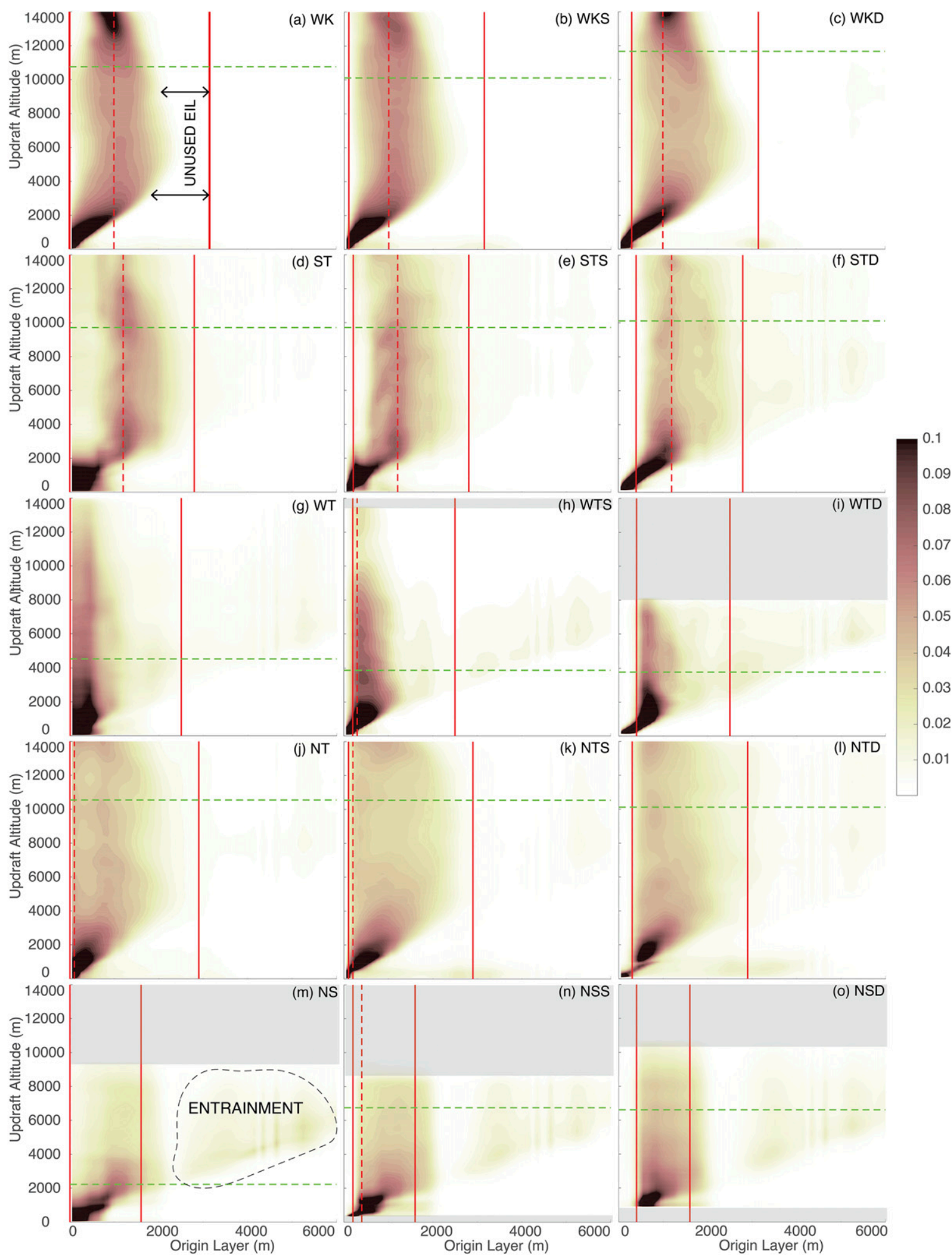

FIG. 4. The frequency distribution of origin height ( $x$ axis; i.e., tracer concentration from each layer) of air composing the 95th percentile updraft core at each altitude ( $y$ axis) is shaded and averaged over the 60-90-min simulation period for each simulation as labeled. Altitudes where the updraft core threshold was less than $1 \mathrm{~m} \mathrm{~s}^{-1}$ are excluded and shaded gray. Solid red vertical lines correspond to the bottom and top of the effective inflow layer derived from each base-state thermodynamic profile, and the most-unstable parcel level is shown with a dashed red line if it is not equal to the surface or the bottom of the effective inflow layer. The average peak updraft height is shown with a horizontal dashed green line. Notations illustrate examples of "unused" EIL air (comprising false alarms as discussed in the text) and air entrained into the updraft core from above the EIL. 
(a) NSD above EIL

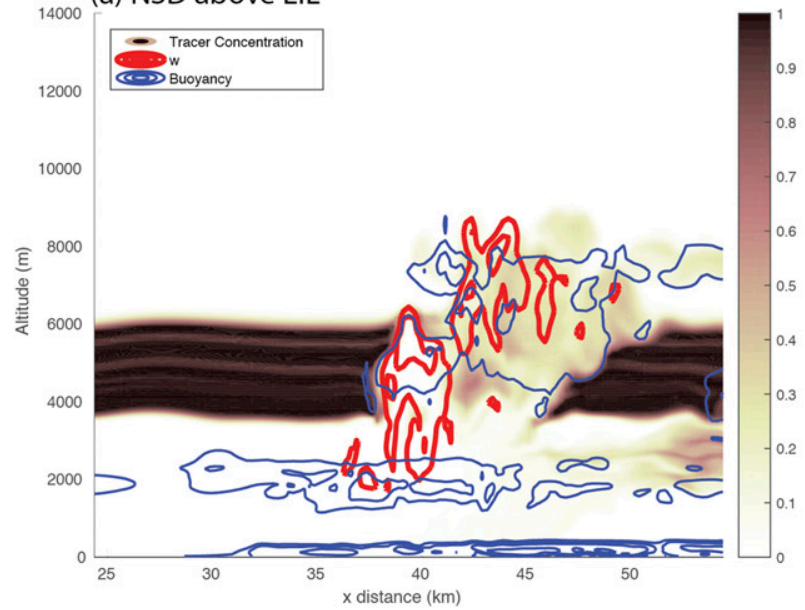

(c) NSD within EIL

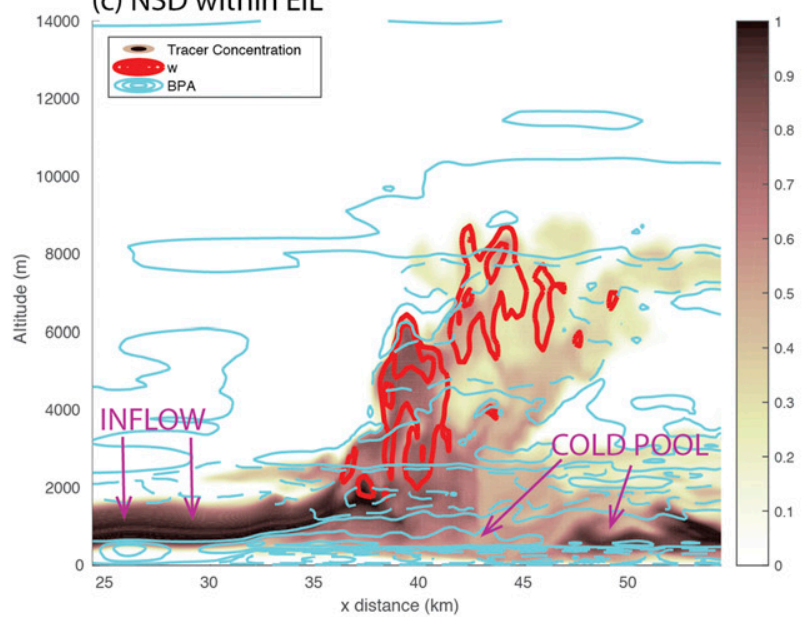

(e) NSD below EIL

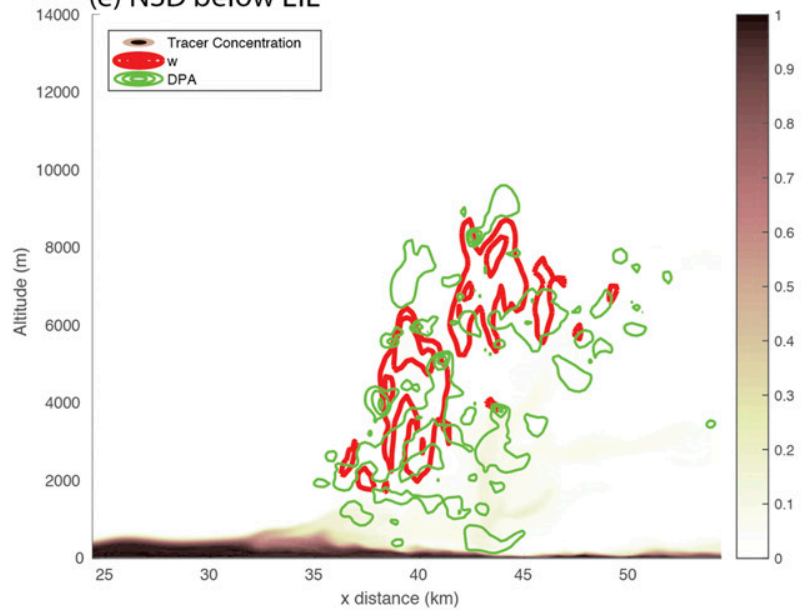

(b) WKD above EIL

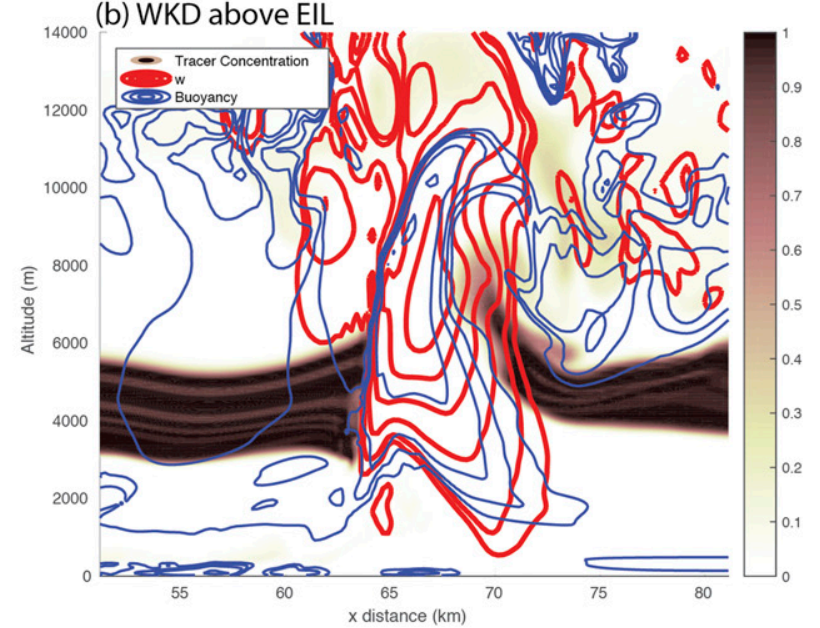

(d) WKD within EIL

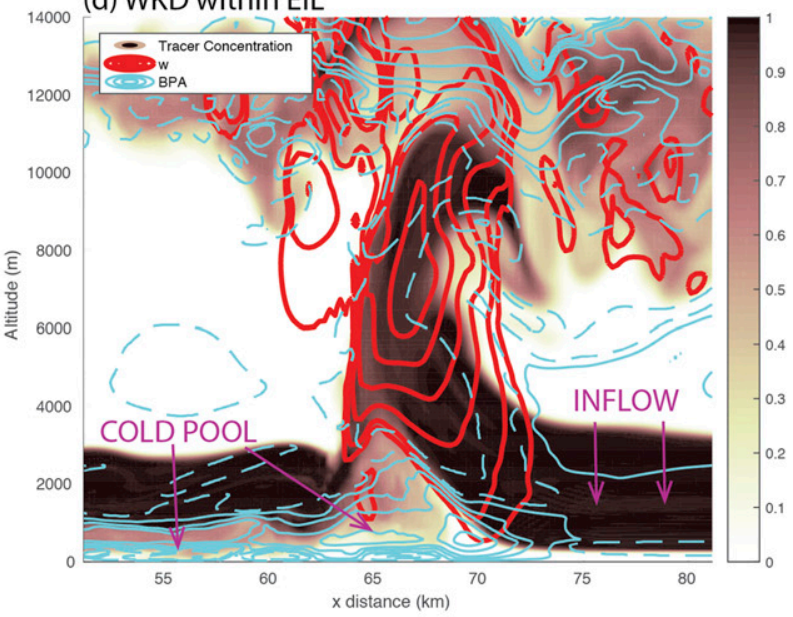

(f) WKD below EIL

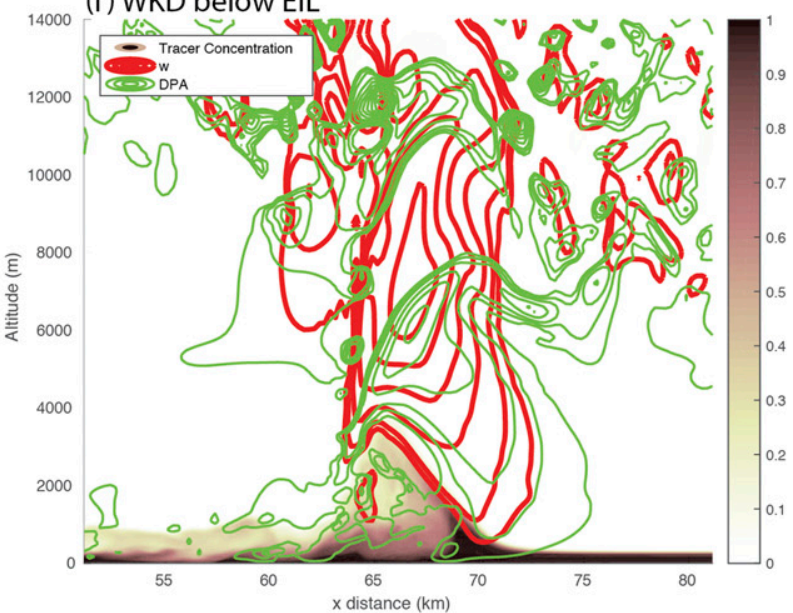

FIG. 5. Vertical cross sections through the peak updraft maximum for the (left) NSD and (right) WKD simulations showing the tracer concentration (shaded) for parcels originating (a),(b) from above the EIL in the 4-6 km layer; (c),(d) from within the EIL; and (e),(f) from below the EIL. Vertical velocity is contoured in red at 5, 10, 20,30, 40, and $50 \mathrm{~m} \mathrm{~s}^{-1}$, while buoyancy, buoyancy pressure perturbation acceleration (BPA), and dynamic pressure perturbation acceleration (DPA) are contoured in blue, cyan, and green, respectively, at 0.01 , 0.05 , and $0.1 \mathrm{~m} \mathrm{~s}^{-2}$ increments thereafter. Negative values are also shown for BPA (dashed cyan lines) at the same contour interval. 
the structural differences found between supercells and nonsupercells in Peters et al. (2020b).

Peters et al. (2019) found that supercell peak updrafts are greater than those of nonsupercells largely because of their enhanced width in regimes with greater lowlevel, storm-relative flow, which protects the updraft core (composed of positively buoyant air originating in the EIL) from entrainment of free tropospheric air, resulting in greater core buoyancy. Despite variations in CAPE between simulations, our results support this finding. The lower thermals of the NSD updraft are comprised of air that is $60 \%-80 \%$ from within the EIL (Fig. 5c), but this fraction falls below $50 \%$ for the upper, weaker thermals that have a significant fraction of air entrained from the 4-6-km layer above the EIL (Fig. 5a). As might be expected, there is relatively little DPA in the NSD updraft, with only small areas of DPA mostly associated with the dynamic low pressure perturbations that form in toroidal updraft circulations in the middle troposphere consistent with Morrison and Peters (2018). Thus, virtually no air from below the EIL participates in this updraft (Fig. 5e). The supercell (WKD) updraft, by contrast, is composed of nearly pure $(>90 \%)$ EIL air as far aloft as $11 \mathrm{~km}$ (Fig. 5d). On the WKD updraft periphery at mid- to upper levels, particularly on the eastern flank, some air is ingested from above the EIL, but this air does not participate in the updraft core (Fig. 5b). Finally, the lower portion of the WKD updraft is collocated with widespread areas of positive DPA, which is associated with lofting of air from below the EIL as far as $3-4 \mathrm{~km}$ aloft, particularly in the outflow region of the supercell, but this air does not participate in the peak updraft farther aloft (Fig. 5f). Below the EIL, BPA is also generally positive in both simulations, but particularly at the leading edge of the WKD outflow (Fig. 5d), providing additional upward forcing for air from below the EIL and within the cold pool, consistent with results of Brown and Nowotarski (2019). BPA is generally negative within the WKD updraft core above $1.5 \mathrm{~km}$.

While Fig. 4 provides a qualitative analysis of the T07 EIL accuracy, we perform a more quantitative analysis of updraft origins relative to the predicted EIL regardless of if the EIL is surface based or elevated for each storm type. Figure 6 shows the percentage of the 95th percentile updraft core originating within, below, and above the EIL at each height averaged over the 60-90-min period of the three simulations for each storm type. First, the WK simulations (Fig. 6a) show the strongest updraft core of any storm type (cf. dashed black lines with other panels), consistent with having the largest magnitudes of $0-6-\mathrm{km}$ shear (Table 1). The
WK simulations also have the smallest proportion of air originating above the EIL, with nearly pure EIL air composing the updraft core above $2 \mathrm{~km}$ (cf. the red line values to black line values for each panel). The ST simulations (Fig. 6b) show significantly more entrainment of air from above the EIL into the updraft core than the WK simulations (cf. red lines in Figs. 6a,b), and a somewhat weaker core updraft, despite having comparable base-state CAPE and deep-layer shear with significantly greater SRH. Indeed, all the supercell simulations based on real environments (ST, WT, NT) have significantly greater fractions of above-EIL air within the updraft core than the WK simulations, suggesting that the WK analytic sounding may result in unrealistically small entrainment (also evident in Figs. $4 \mathrm{a}-\mathrm{c}$ ). The WT simulations have significantly weaker updraft cores and greater above-EIL entrainment than the other supercells (Fig. 6c), which is perhaps unsurprising given that these base states have the weakest CAPE and deep-layer shear of all the supercell simulations, including the NT supercells (Fig. 6d). As might be expected from the analysis of Fig. 5, the NS simulations (Fig. 6e) exhibit considerable entrainment of above-EIL air; in fact, more air within the core updraft above $4 \mathrm{~km}$ comes from above the EIL than within it (e.g., the black and red lines have similar values between 4 and $8 \mathrm{~km}$ ).

Regardless of storm type, air from below the EIL does not form a significant fraction of the core updraft above $2-3 \mathrm{~km}$. This is not surprising, given this air is excluded from the T07 EIL metric precisely because it does not have appreciable CAPE. Nowotarski et al. (2011) showed that some of the air entering the 4-km updraft in their simulations originated within low-level stable layers, but their analysis did not examine whether this air had appreciable CAPE, and they adopted a weak vertical velocity threshold for their definition of "updraft." This analysis suggests that below-EIL air does not meaningfully contribute to the updraft core in the mid- to upper troposphere. However, the fraction of the low-level $(1 \mathrm{~km})$ updraft composed of below-EIL air varies between storm types. The WK and tornadic supercells loft below-EIL air higher than the NT and NS simulations, which would be consistent with stronger low-level dynamic lifting of this negatively buoyant air, hypothesized to be critical for tornadogenesis.

We can consider the T07 EIL metric as a forecast of the air that will participate in the updraft core. Within this forecast framework, the percentage of updraft core air that originates from within the sounding-derived EIL is equivalent to the probability of detection (POD; i.e., nonzero tracer concentration within the red lines on Fig. 4 and black lines in Fig. 6), and the percentage of the 
(a) WK Simulations

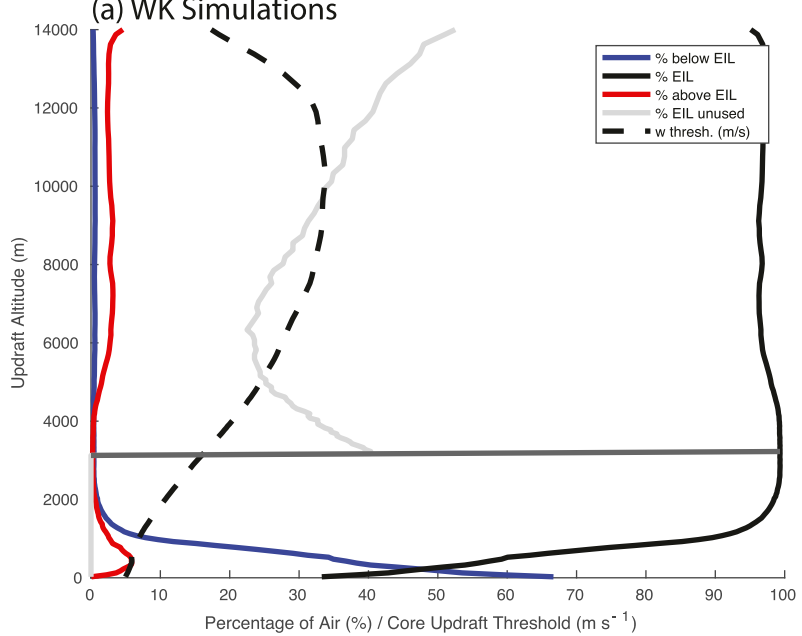

(c) WT Simulations

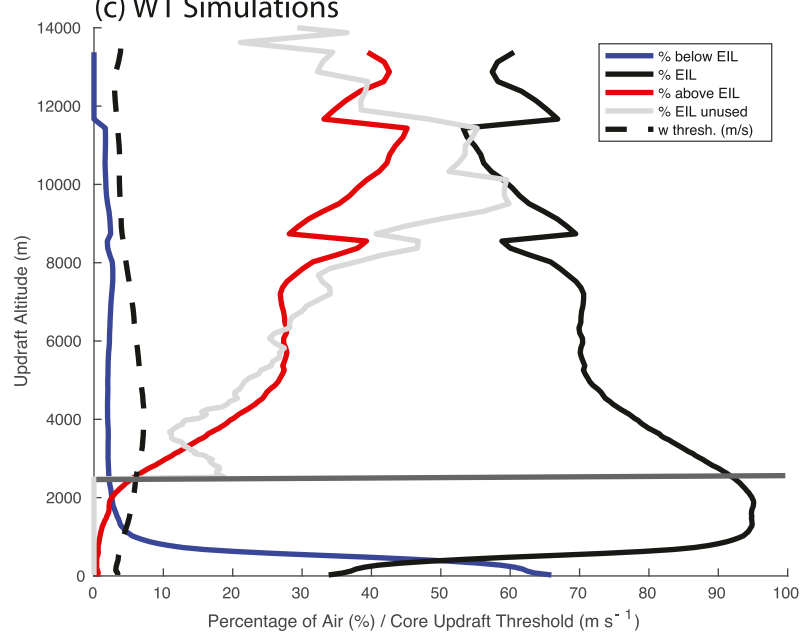

(b) ST Simulations

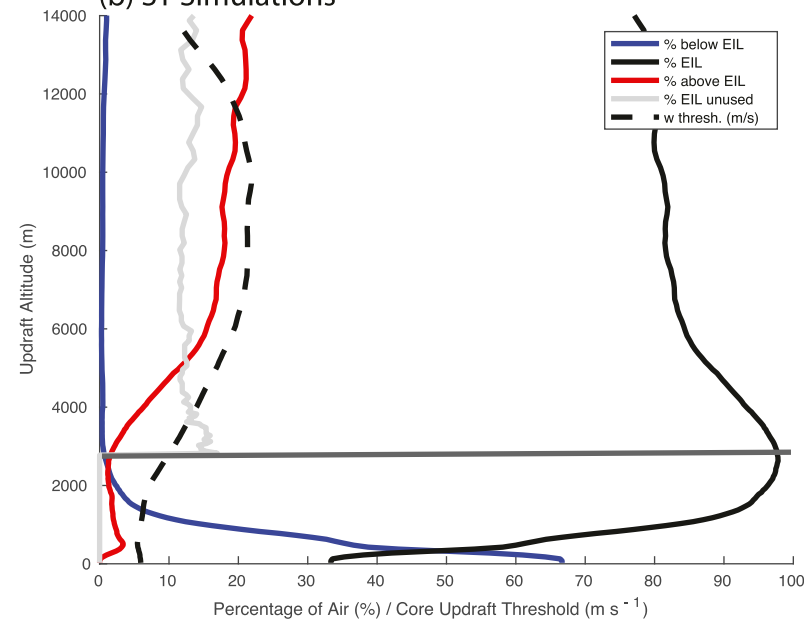

(d) NT Simulations

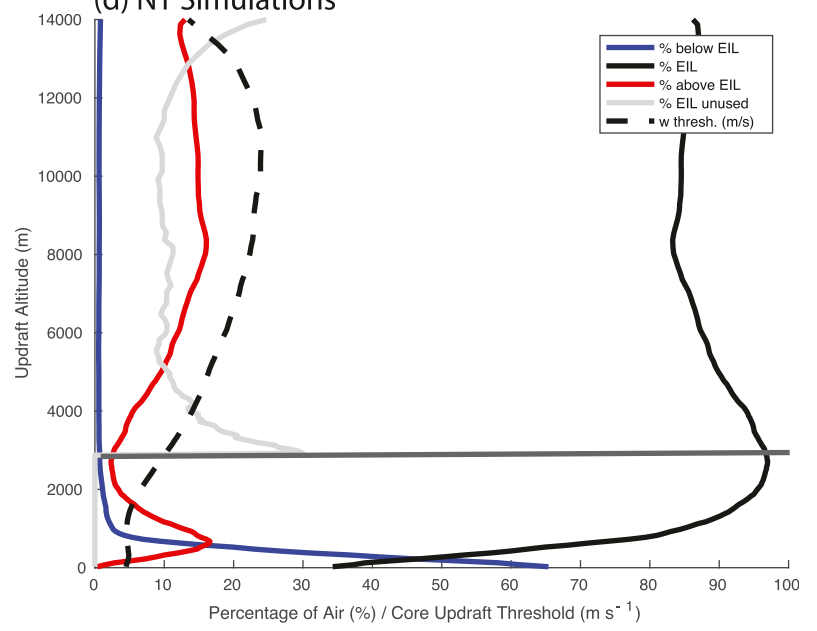

(e) NS Simulations

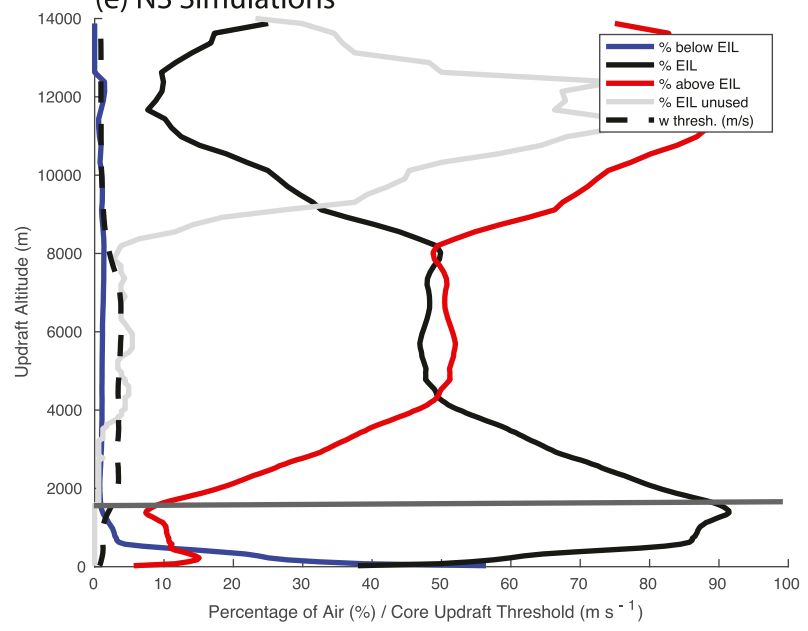

FIG. 6. Vertical profiles of the percentages of air within the 95th percentile updraft core (corresponding vertical velocity shown in black dashed lines) at each height originating below (blue), within (black), and above (red) the EIL. Shown in light gray is the percentage of the total EIL depth that does not participate (i.e., is "unused") in the updraft core at each height above the top of the EIL (horizontal dark gray line). Each panel is averaged over the three simulations for each storm type and over the simulation time period of $60-90$ min. 
sounding-derived EIL that does not meaningfully participate in the updraft core $^{4}$ is equivalent to the false alarm ratio (FAR; i.e., annotated white space in Fig. 4a and gray lines in Fig. 6). These results suggest that, at least for a definition of updraft core using the 95th percentile of vertical velocity as the threshold, the POD of the EIL is limited by entrainment of air from above the EIL, and not air from below it (Fig. 7d). It should be noted that this forecast framework (e.g., using POD and FAR concepts) is intended to provide an objective analysis of EIL performance rather than an explicit measure of practical forecast skill. For instance, we recognize that the T07 EIL parameter was never intended to account for entrainment and forecasters do not use it to do so; however, entrained air that enters the updraft core still serves to dilute the updraft core and alter its properties from those that might be expected if the EIL were the only origins of updraft core air. For this updraft-core threshold (Fig. 8d), the POD for the peak (i.e., maximum vertical velocity at any level) updraft core ranges from $40 \%$ to $99 \%$, with the poorest performance (i.e., greatest entrainment) in the nonsupercell simulations. Alternatively, the FAR ranges from $0 \%$ to $45 \%$ for all simulations, with the lowest FAR for the nonsupercell and deep-stable layer simulations, wherein the EIL depth (i.e., EIL top minus EIL base) is generally the smallest (Table 1).

Using the above definitions of POD and FAR, the critical success index (CSI) or threat score can be defined as (Gerapetritis and Pelissier 2004)

$$
\mathrm{CSI}=\frac{1}{1 /(1-\mathrm{FAR})+(1 / \mathrm{POD})-1}
$$

Thus, the CSI is maximized when the POD is large and the FAR is small, such that forecast skill is best with a CSI equal to 1 . The distribution of the peak updraft core EIL CSI for the 95th percentile updraft core definition shows a median CSI for these simulations of 0.64 . The maximum EIL CSI is for the NTD simulation $(\mathrm{CSI}=0.78)$ and the minimum is for the NS simulation $(\mathrm{CSI}=0.44)$. It should be noted that the CSI equally weights false alarms (higher FAR) and missed events (lower POD) such that the index alone gives an incomplete understanding of forecast skill. Following Roebber (2009), we plot the POD versus the success ratio $(1-$ FAR $)$ in

\footnotetext{
${ }^{4}$ Herein we consider any passive tracer level with a concentration of less than $2 \%$ as "not meaningfully participating" in the updraft core at any height. These parcels may still be lifted or even become positively buoyant, but we consider them "unused" in this evaluation if they do not participate in the updraft core, as defined by a given vertical velocity percentile threshold.
}

performance diagrams (Fig. 8). Thus, while forecast skill (i.e., CSI) increases to the upper right of the diagram, changes in CSI can be placed in the context of changes in both POD and FAR, commonly referred to as forecast bias. There is no clear trend as to which storm types or stable layer depths exhibit the best EIL forecast skill, but it does seem clear that the EIL generally has the poorest forecast skill for the nonsupercell simulations, consistent with their large entrainment (Fig. 6e) and low POD (Fig. 8d) with this updraft core definition.

\section{b. Comparison of EIL performance for varied updraft core definitions}

So far, our discussion of EIL performance has been limited to forecasts of the origins of air comprising the updraft core, where updraft core is defined based on the 95th percentile of vertical velocity exceeding $0.1 \mathrm{~m} \mathrm{~s}^{-1}$ occurring within a $30 \mathrm{~km} \times 30 \mathrm{~km}$ subdomain centered on the right-moving supercell (or maximum vertical velocity for nonsupercell simulations) at each height. This definition was chosen in part because visual analysis of this threshold suggests it identifies the main updraft in each supercell simulation with little ancillary convection. Perhaps more relevant to severe weather forecasting, the average vertical profile of this threshold averaged over all simulations reaches a peak value of approximately $20 \mathrm{~m} \mathrm{~s}^{-1}$ (Fig. 7d), roughly corresponding to the terminal velocity of a severe (1in.) hailstone (Markowski and Richardson 2010). Thus, for the supercell simulations here, the 95th percentile corresponds to updraft speeds capable of producing severe weather. However, other forecasting applications (e.g., lightning, flash flooding, severe winds) may require forecasts of updraft origins over a different definition of updraft core. Therefore, to answer our second research question, we examine EIL performance over several updraft core threshold definitions: the 50th, 75th, 90th, 95th, and 99th percentile of vertical velocity at each height.

In general, as the updraft core threshold is reduced the fraction of entrained air into the core updraft increases. For low updraft core thresholds (50th and 75th percentiles), the corresponding vertical velocity is quite weak $\left(<5 \mathrm{~m} \mathrm{~s}^{-1}\right)$ and about half of the air comprising the mid- to uppertropospheric updraft core is entrained from above the EIL (Figs. 7a,b). Thresholds at and above the 90th percentile (Figs. 7c,d,e), exhibit a reduction in the entrained air above the EIL, though even for the most strict definition of updraft core (99th percentile), approximately $20 \%$ of the peak updraft air is entrained from above the EIL, on average. Similar analysis as that of Fig. 6 for other thresholds (not shown) suggests, however, that most of this entrainment occurs in the NS and WT simulations. Regardless of updraft core threshold, the amount of 
(a) 50th Percentile

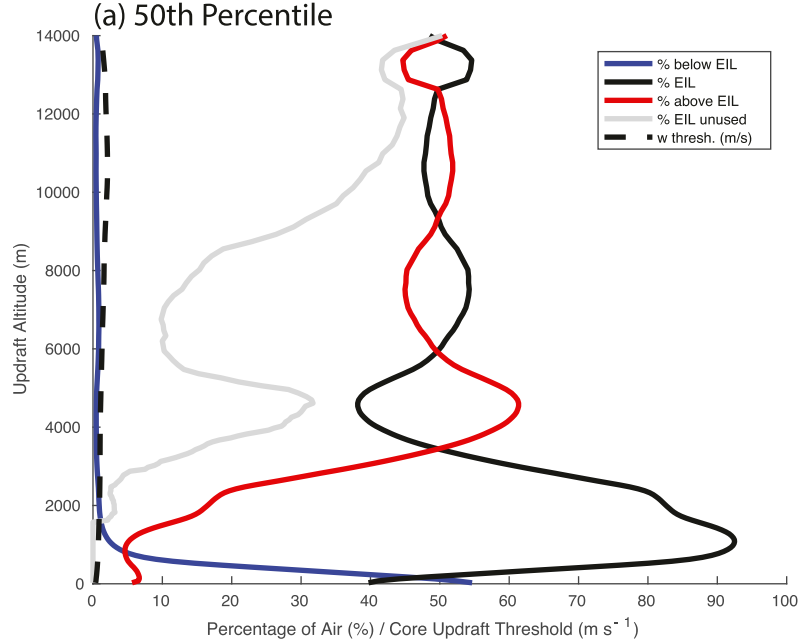

(c) 90th Percentile

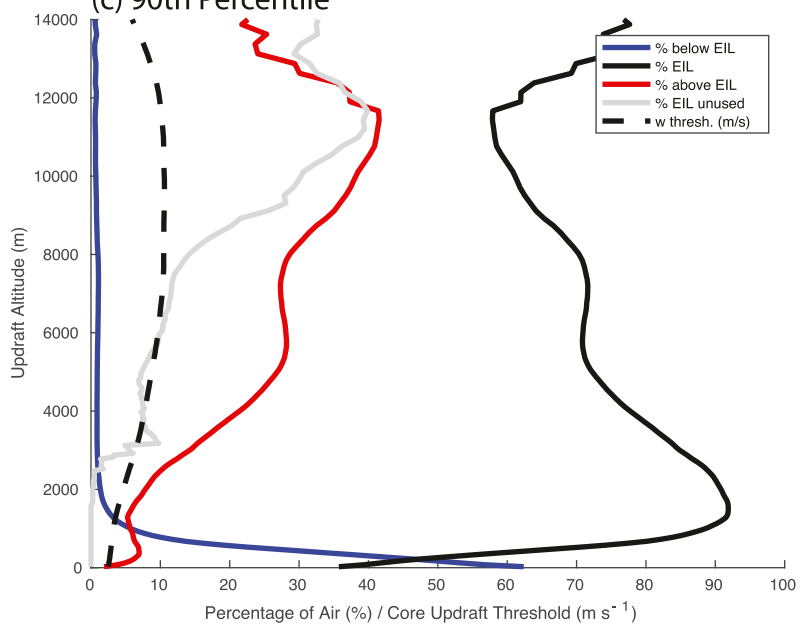

(e) 99 th Percentile

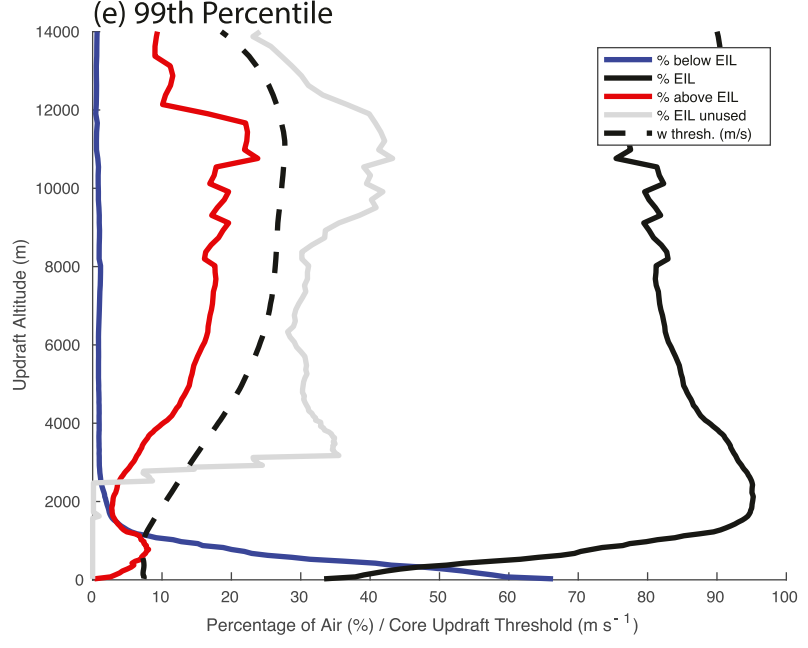

(b) 75th Percentile

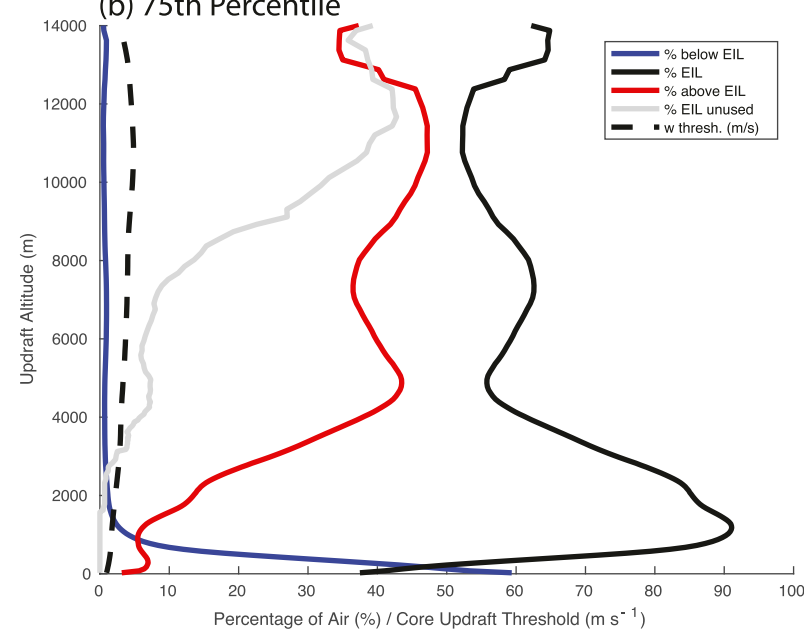

(d) 95th Percentile

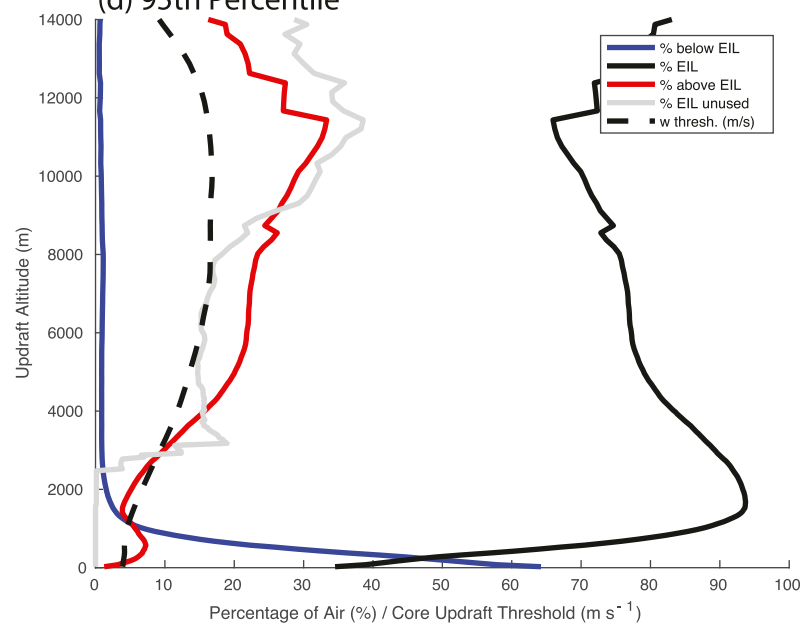


(a) 50th Percentile

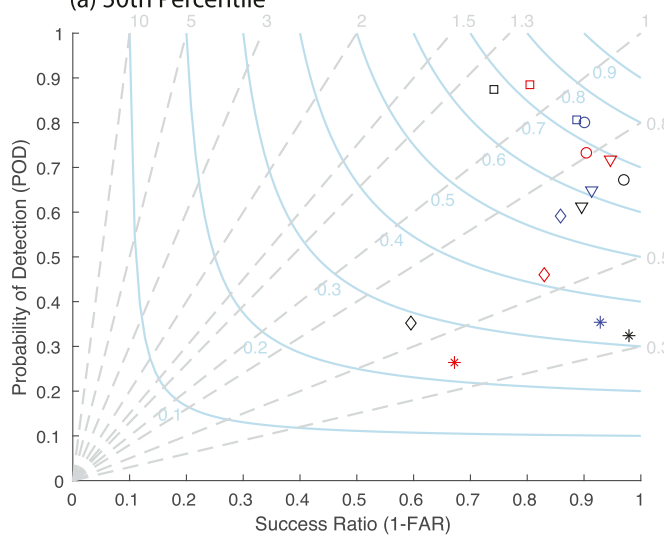

(c) 90th Percentile

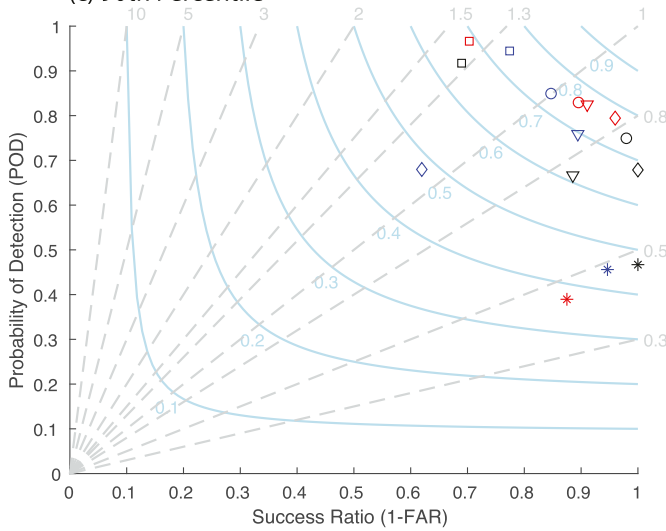

(b) 75th Percentile

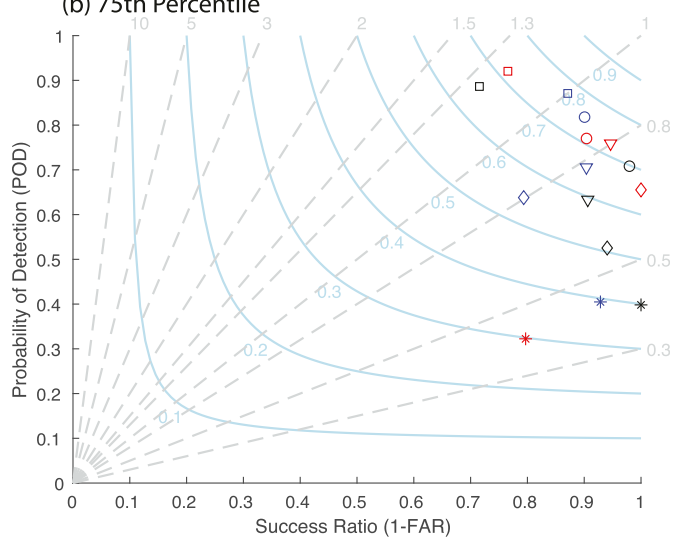

(d) 95th Percentile

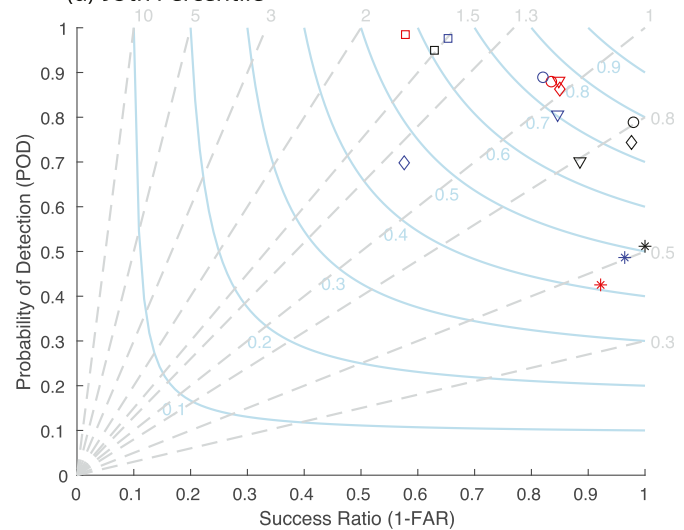

(e) 99th Percentile

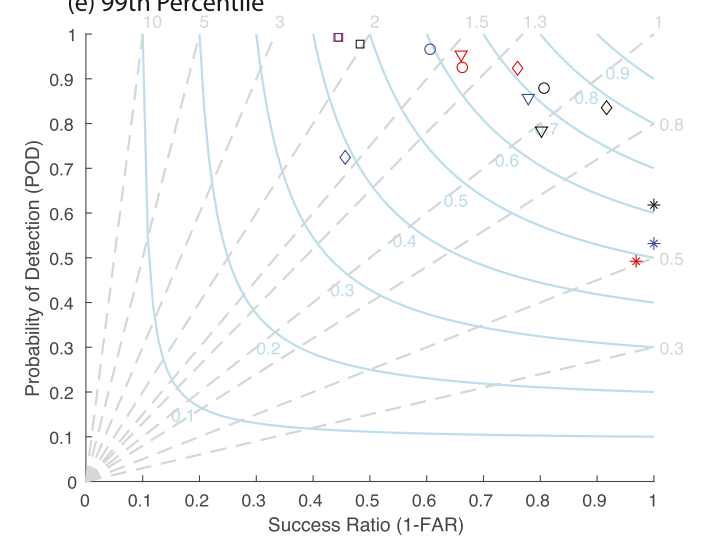

N S D

$\square \square \square \mathrm{WK}$

$\nabla \nabla \nabla$ ST

$\diamond \diamond \diamond \mathrm{WT}$

$\circ \circ \circ \mathrm{NT}$

* * * NS

FIG. 8. Performance diagrams for the EIL as a forecast of air participating in the peak updraft for various updraft core threshold definitions for each simulation. Probability of detection (POD) and success ratio for this context are defined in the text. Forecast bias is shown in dashed gray lines, and critical success index (CSI) is shown in light blue lines.

EIL air that does not participate in the updraft tends to increase with height. Again, this trend is likely driven by the relatively weak and shallow updrafts in the NS and WT simulations. In general, for simulations with relatively high percentages of "unused" EIL, air that does not participate in the peak updraft core tends to come from the upper few hundred meters of the EIL (not shown), where CAPE (CIN) is substantially decreased (increased) from its maximum (minimum) value, but still meets the T07 EIL criteria.

Returning to the EIL-as-forecast framework described in the previous section, we can compare the T07 EIL metric forecast skill for each updraft core threshold. Figure 8 shows performance diagrams where the FAR is equivalent to the percentage of EIL unused by the updraft core at the level of maximum vertical velocity in 

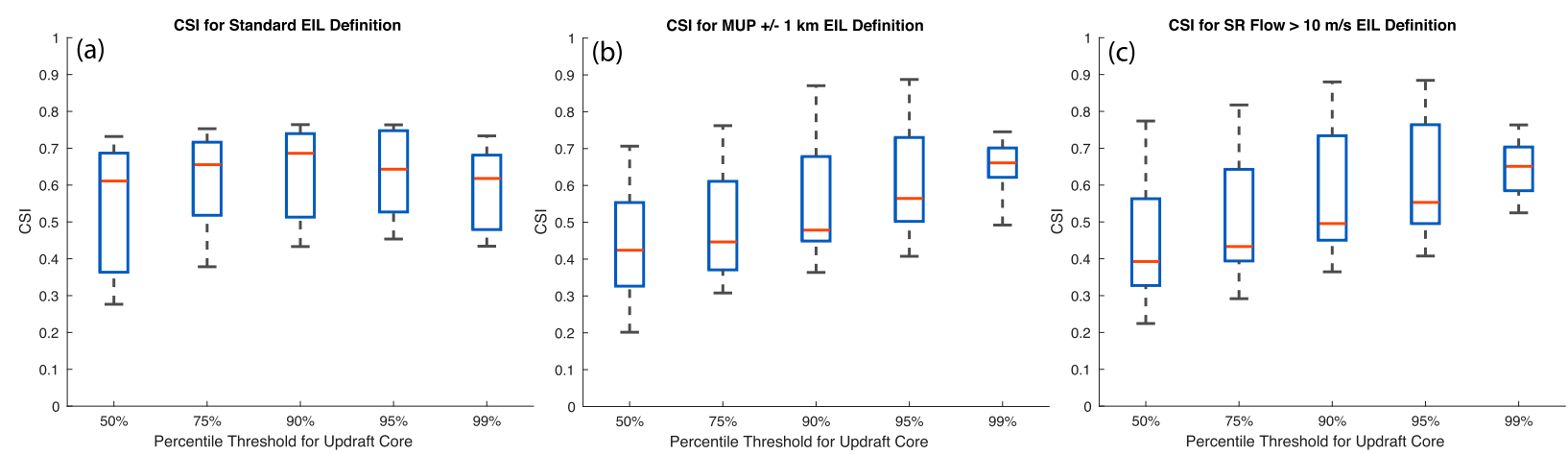

FIG. 9. Distributions of the critical success index (CSI) of the EIL forecast of origin level for parcels within the updraft core at the level of peak updraft in each simulation for (a) the standard EIL definition, (b) a variation including only parcels within the EIL within $1 \mathrm{~km}$ of the most-unstable parcel (MUP) level, and (c) a variation including only parcels within the EIL with storm-relative (SR) flow greater than $10 \mathrm{~m} \mathrm{~s}^{-1}$. Distributions are shown for five percentile thresholds for the updraft core definition.

each simulation averaged over the 60-90 min simulation period (i.e., the "peak" updraft) and the POD is equivalent to the percentage of the peak updraft core composed of air from the T07 EIL for each threshold. ${ }^{5}$ In general, there is a transition from lower FAR (i.e., higher success ratio) and lower POD toward higher POD and higher FAR (i.e., lower success ratio) as the updraft core threshold is increased, suggesting a trade-off that limits overall forecast skill. In other words, the bias increases as the updraft core threshold becomes more stringent. Consistent with earlier analysis showing notably low entrainment, the WK simulations (hollow boxes in Fig. 8) tend to have the highest POD for all thresholds, but their FAR also tends to be highest, consistent with the greatest EIL depth. A notable exception to the trend of increasing FAR (i.e., decreasing success ratio) at greater updraft core thresholds are the NS simulations, which show a reduction in the percentage of the EIL unused by the updraft core (i.e., FAR) as the threshold increases (asterisks in Fig. 8). For the supercell simulations initialized in real environments (ST, WT, NT), there is no notable trend toward greater or less skill in any one storm type across all updraft thresholds. Finally, there is also no notable pattern between the depth of the surface inversion (i.e., red, blue, and black symbols) and either the POD or FAR.

Consistent with the aforementioned trade-off between POD and FAR, the median CSI is similar regardless of the updraft core definition (0.6-0.7; Figs. 8 and 9$)$. The spread in CSI tends to decrease as the updraft core threshold increases, particularly above the 50th percentile definition. While the median CSI is slightly

\footnotetext{
${ }^{5}$ By convention, a performance diagram plots the success ratio on the $x$ axis, but the success ratio $=1-$ FAR, such that an increasing success ratio represents a decreasing FAR.
}

higher for the 90th percentile threshold, the minimum, maximum, and quartile values are all higher for the 95th percentile threshold. Apart from the generally poor performance for the NS, NSS, and NSD simulations, there is no clear trend toward greater CSI in any particular storm type (Fig. 8). As might be expected from the previous discussion of decreasing FAR in the NS simulations, improvements in CSI (particularly in the lowest quartile) are driven by increasing performance for the NS simulations. Thus, these results suggest that the T07 EIL metric exhibits robust skill in predicting the origins of peak updraft across a range of updraft core definitions, EIL depths, and EIL base heights, particularly for supercell storm types. It should be noted here that we have not evaluated the EIL performance for mesoscale convective systems (MCSs), where the large influence of the cold pool on updraft organization and propagation may alter our results.

\section{c. Alternative EIL formulations}

While the POD of the T07 EIL metric generally improved as the updraft core threshold increased, the concurrent increase in FAR results in an upper limit to the forecast skill of the standard T07 EIL metric. Thus, as potential improvements to the sounding-derived EIL forecast metric, we examined two ways to further constrain the EIL depth to reduce the FAR while maintaining the high POD of larger updraft core thresholds.

Our first new constraint was motivated by analysis of the distribution of passive tracer origin heights within the updraft core (Fig. 4), which suggest that this distribution is generally centered on or near the MU parcel (MUP) level. To incorporate this finding, we added an additional thermodynamic criterion to limit the EIL depth - requiring that, in addition to meeting the original T07 CAPE and CIN criteria, parcels originate within a fixed vertical distance of the MUP within a sounding. 
Figure 9b shows the distribution of CSI for EIL with the additional 1-km from MUP criterion, which resulted in the best skill of any distance tested $(200 \mathrm{~m}, 500 \mathrm{~m}, 1 \mathrm{~km})$. Compared to the standard T07 EIL metric (Fig. 9a), the spread in skill across updraft core thresholds increases. For lower updraft core thresholds (50th, 75th, 90th percentiles), the new EIL median CSI decreases substantially. At the most stringent updraft core threshold (99th percentile), the median CSI for the new EIL metric increases relative to the T07 EIL, and the interquartile range decreases substantially. The steady increase in skill as the updraft threshold increases indicates that this method is successful in limiting the additional FAR at larger updraft thresholds seen with the T07 EIL.

Our second attempt to further constrain the EIL metric was based on recent research that suggests updraft purity (i.e., the fraction of air from within the EIL) increases as the low-level, storm-relative (SR) flow increases (e.g., Peters et al. 2019). As such, we added a kinematic criterion to the T07 EIL metric-requiring that, in addition to meeting the original T07 CAPE and CIN criteria, parcels must also originate within the deepest contiguous layer with SR flow [defined based on the Bunkers et al. (2000) sounding-derived storm motion] exceeding a specified threshold within a sounding. We tested three SR-flow thresholds: 5,10 , and $15 \mathrm{~m} \mathrm{~s}^{-1}$. In cases where no contiguous layer of air met both the T07 thermodynamic criteria and our SR-flow threshold, we reverted to the standard T07 EIL metric (this was typical in the NS base state and occasional in the NT base state). The greatest skill came with the $10 \mathrm{~m} \mathrm{~s}^{-1}$ SR-flow threshold (Fig. 9c), perhaps reflective of earlier work showing this threshold is generally exceeded for supercell thunderstorms (Droegemeier et al. 1993). Like our MUP-based modification, the SR-flow criterion increases the range in forecast CSI and substantially decreases the median skill at the lower updraft core thresholds relative to the standard T07 EIL metric. Again, steadily increasing CSI as the updraft threshold is increased indicates that POD increases while holding FAR relatively constant. Finally, like the MUP-based modification, the best performance is at the 99th updraft core threshold, where the median is higher than the T07 EIL and the interquartile range is reduced.

Overall, both modifications suggest that EIL FAR can be reduced from the standard T07 EIL metric, though it often comes at the expense of decreased POD for some simulations. Indeed, simulations with the least entrainment, highest POD, and deepest EILs (the WK simulations) see considerable CSI improvements (CSI $>0.8$ in some cases, not shown). The greatest potential improvements by constraining the EIL based on either proximity to the MUP or SR-flow come at the highest updraft thresholds, suggesting that any such modifications would primarily benefit forecasting supercellular convection with severe hazards. However, these are not substantial improvements from the T07 EIL definition, which has the added benefit of consistent CSI across a range of updraft definitions. Applying both the SR-flow and MUP criteria simultaneously does not result in significant changes in the EIL depth or skill for our sample of simulation base states, since the majority of layers within $1 \mathrm{~km}$ of the MUP level have SR flow exceeding $10 \mathrm{~m} \mathrm{~s}^{-1}$.

\section{d. Dependence of EIL performance and updraft forcing on environmental parameters}

Our final research question is concerned with the aspects of the near-storm environment that might dictate EIL performance and updraft strength overall. Again using the 95th percentile threshold for our definition of updraft core, we compared the EIL CSI for predicting the peak updraft origin as a function of a wide range of sounding-derived parameters (many of which are shown in Table 1) that might potentially influence the peak updraft strength and EIL. The majority of relationships have statistically insignificant correlations (using a $p<$ 0.05 threshold for statistical significance), but all figures displaying a correlation coefficient have a statistically significant correlation. ${ }^{6}$ EIL CSI is moderately correlated with both MUCAPE (Fig. 10a) and 0-6-km bulk wind difference (Fig. 10b). These variables are also the strongest predictors of peak updraft strength (Fig. 11), suggesting along with earlier results, that EIL performance may increase with peak updraft strength. This is consistent with the result that stronger peak updrafts in the WK, ST, and NT simulations generally have the smallest fraction of entrained air from above the EIL (entrainment would reduce updraft speed via dilution of core buoyancy) and highest EIL POD (Fig. 8).

Peters et al. (2019) showed that low-level SR flow magnitude also increases peak updraft strength. Not surprisingly, average SR flow over the $0-3-\mathrm{km}$ layer is also moderately correlated $(r=0.55)$ with EIL CSI in our simulations. There is also a strong correlation between 0-6-km shear and 0-3-km SR flow (Table 1; $r=0.95$ ), consistent with Peters et al. (2019) finding that the link between deep-layer shear and supercell updraft intensity is primarily due to its association with stronger low-level SR flow and wider updrafts.

\footnotetext{
${ }^{6}$ Though it is often difficult to ascribe qualitative importance to correlation values beyond their statistical significance, we classify $r<0.50$ as a weak correlation, $0.50<r<0.75$ as moderate, and $r>0.75$ as strong.
} 

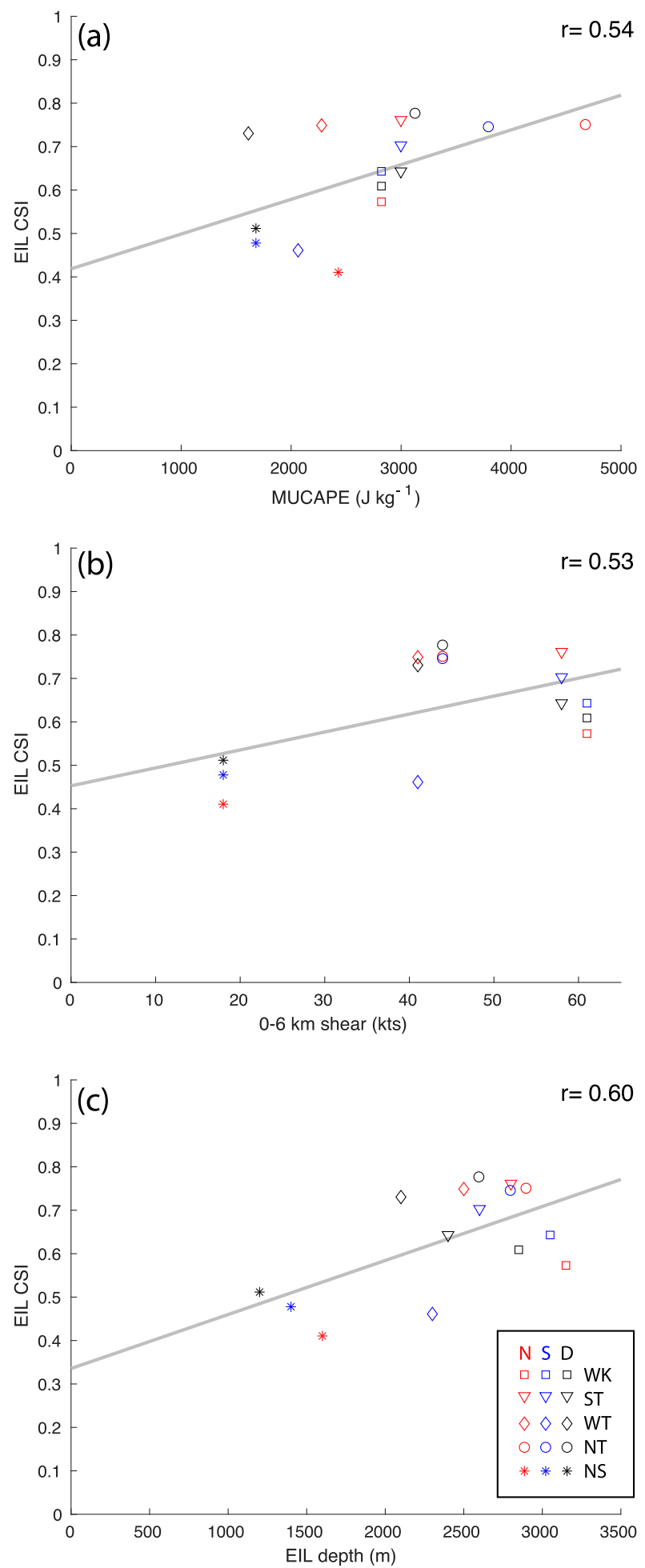

FIG. 10. Scatterplots of average CSI of the EIL forecast of origin level for parcels within the updraft core at the level of peak updraft, with the 95th percentile definition of updraft core with (a) mostunstable (MU) CAPE $\left(\mathrm{J} \mathrm{kg}^{-1}\right)$, (b) 0-6-km vertical wind shear (kt), and (c) EIL layer depth ( $\mathrm{m})$ in the base state of each simulation.
Somewhat surprisingly there is not a statistically significant correlation between peak updraft speed and EIL CSI (not shown). This is because EIL CSI is also moderately correlated with EIL depth (Fig. 10c), and the simulations with the deepest EILs do not necessarily exhibit the strongest peak updrafts. Regardless of the connection to peak updraft strength, these results indicate that the T07 EIL metric is likely to exhibit higher skill in environments with stronger CAPE and deep-layer shear.

The results discussed above suggest that the link between EIL performance and the storm environment may be associated with factors that dictate updraft forcing and intensity. Therefore, to better understand the connection between the near-storm environment and low-level and peak updraft intensity, we compared sounding-derived parameters with the 1-km updraft and peak updraft strength (Fig. 11) and updraft forcing terms (Figs. 12-14). The 1-km updraft strength is strongly correlated with deep-layer shear (Fig. 11a), strongly correlated with $0-3 \mathrm{~km}$ and effective layer average SR flow ( $r=0.81, r=0.78$, respectively), and moderately correlated with the ESRH (Fig. 11c). We also examined the relationship between $0-1$ and $0-3 \mathrm{~km}$ fixed-layer $\mathrm{SRH}$ with the $1-\mathrm{km}$ updraft, but found no statistically significant correlation with either-thus highlighting the utility of using SRH integrated over the EIL, particularly in environments with surface-based stable layers. Interestingly, the 1-km updraft strength has a positive, statistically significant correlation with MUCAPE (not shown) and MLCAPE (Fig. 11e). This is surprising because updraft parcels are typically negatively buoyant at $1 \mathrm{~km}$ (Fig. 12), which is below the LFC for most simulations. Indeed there is a negative (though not statistically significant) relationship between the 1-km updraft strength and the buoyancy averaged over the 1-km core updraft (Fig. 13a). There are two possible interpretations of this result. One is that CAPE and shear may be inadvertently related in our small sample size. This is possible considering the simulations with the highest MUCAPE (NT, NTS, NTD) have significantly larger MUCAPE than the simulations with the weakest deep-layer shear (NS, NSS, NSD) as shown in Table 1. Indeed, this may be the most likely explanation as there is a weak positive, albeit insignificant correlation between MUCAPE and deep-layer shear in the 15 base states (not shown).

If the potential relationship between CAPE and shear in our sample size does not fully explain the positive correlation between MUCAPE and 1-km updraft strength, it is possible that there is a physical explanation. One such explanation is that the BPA, which tends to be positive at low levels, especially in the WK and ST simulations 

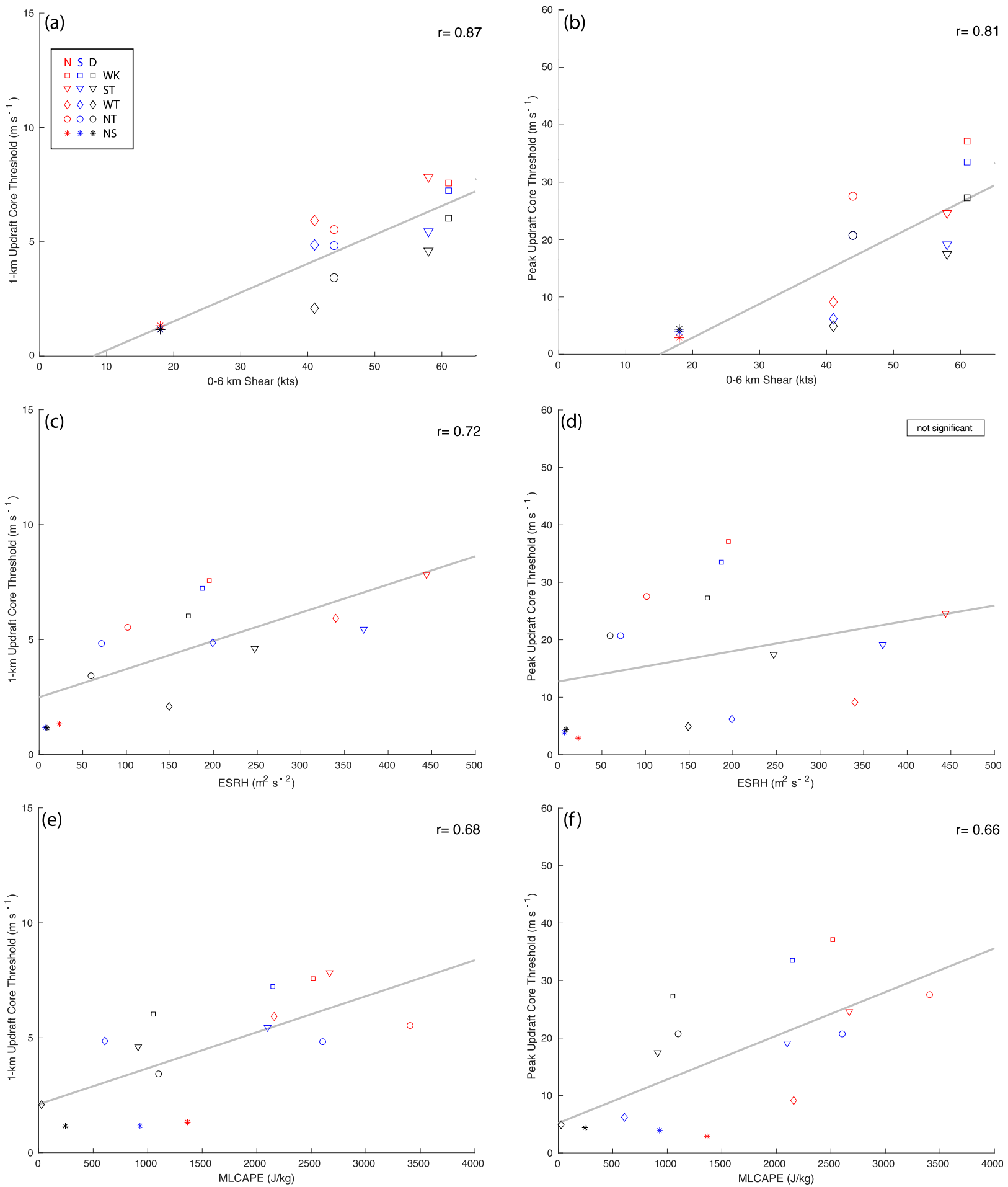

FIG. 11. Scatterplots of sounding-derived parameters and (left) 1-km and (right) peak updraft 95th percentile updraft core threshold for each simulation. Correlations with $p>0.05$ are considered "not significant." 
(a) WK

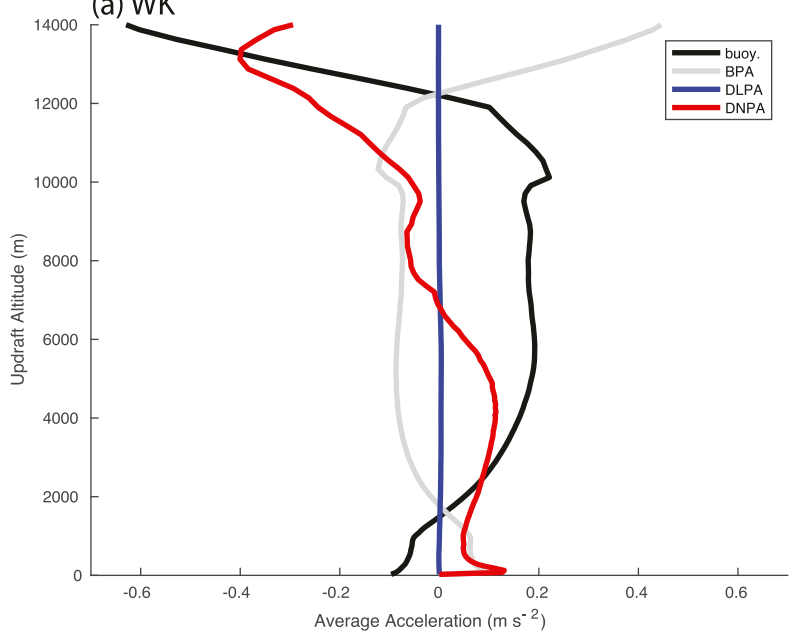

(c) WT

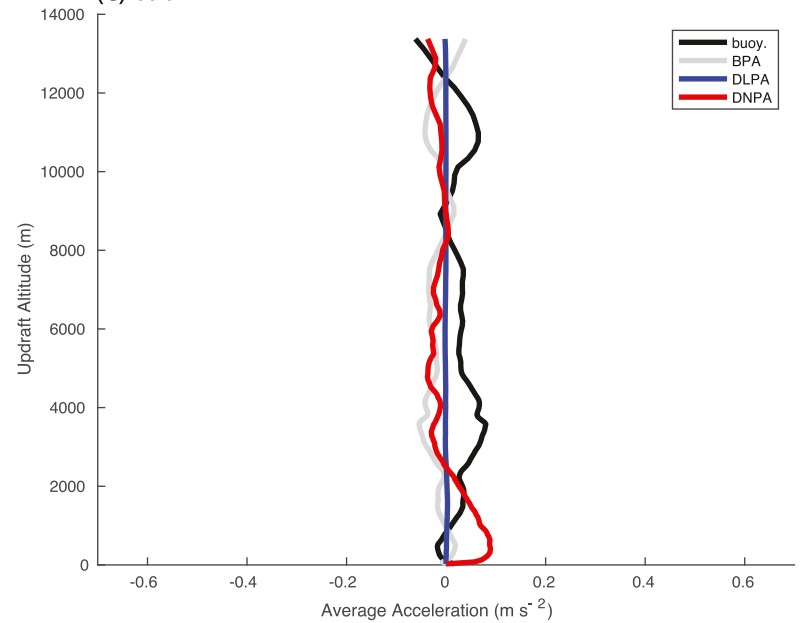

(e) NS
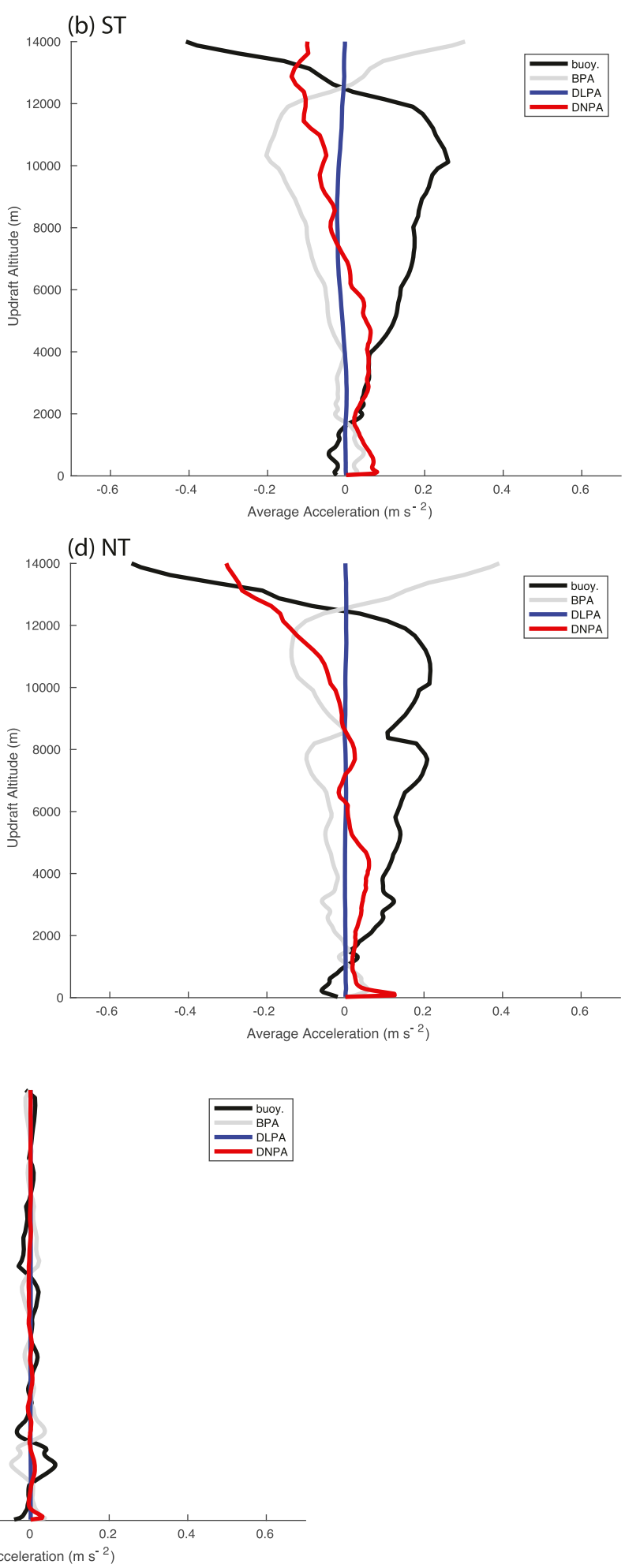

FIG. 12. Vertical profiles of updraft forcing terms averaged over the 95th percentile threshold updraft core at each height for the (a) WK, (b) ST, (c) WT, (d) NT, and (e) NS simulation. Each panel is averaged over the simulation time period of 60-90 min. 

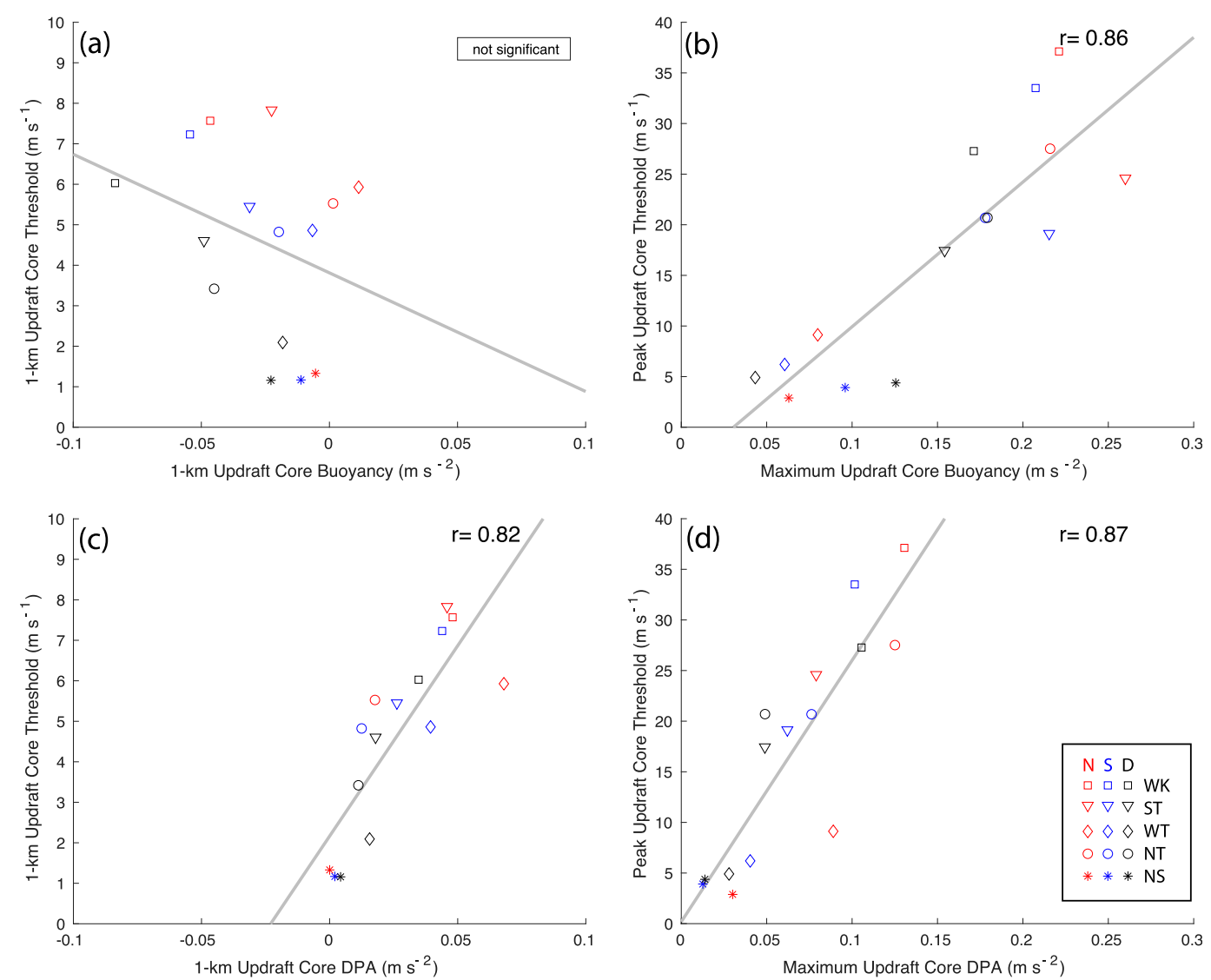

FIG. 13. Scatterplots between (left) 1-km updraft or (right) peak updraft 95th percentile updraft core thresholds and (top) buoyancy or (bottom) dynamic pressure acceleration (DPA). Correlations with $p>0.05$ are considered "not significant."

(Figs. 12a,b), increases at low levels as MUCAPE increases. However, there is only a very weak, statistically insignificant correlation between the 1-km updraft core BPA and CAPE (not shown) and a weak statistically insignificant correlation between 1-km updraft strength and BPA averaged over the 1-km updraft core (not shown), limiting the likelihood of this scenario. In any case, there is a moderate, statistically significant correlation $(r=0.64)$ between the percentage of air from below the EIL that participates in the 1-km updraft core and MLCIN, which may be partly explained by the positive (but not statistically significant) correlation between MLCIN and BPA averaged over the $1-\mathrm{km}$ updraft core (not shown). Thus the potential role of BPA in low-level updraft forcing remains uncertain, and should be explored in more detail in future studies with a larger sample of cases.

Regardless of the potential role of BPA, it seems clear that dynamic updraft forcing (DPA) plays a large role in the low-level updraft forcing. Every storm type displays positive nonlinear DPA in the lowest few hundred meters of the updraft core (Fig. 12), potentially caused by either a dynamic pressure maximum at the surface associated with convergence along the gust front and/or dynamic pressure minimum aloft driven by elevated rotation. Indeed, nonlinear DPA tends to be the largest updraft forcing over the lowest $2 \mathrm{~km}$ of each supercell storm type, consistent with findings of Weisman and Rotunno (2000) for idealized hodograph shapes. Interestingly, the two tornadic storm types (ST, WT; it is not clear if the WK base-state would produce a tornado in nature) display slightly deeper layers of enhanced nonlinear DPA (Figs. 12b,c). The linear DPA term is close to zero at all levels of each simulation updraft core. This is not surprising, as linear dynamic pressure perturbations exist somewhat symmetrically around the updraft core in areas of strong horizontal gradients in vertical velocity, thus their contribution to the DPA averages out over the updraft maximum. The 1-km DPA shown to be largely responsible for low-level updrafts in these simulations is strongly correlated with environmental ESRH (Fig. 14a) and moderately correlated with deeplayer shear (Fig. 14b), likely explaining the relationship between these parameters and low-level updraft strength. 

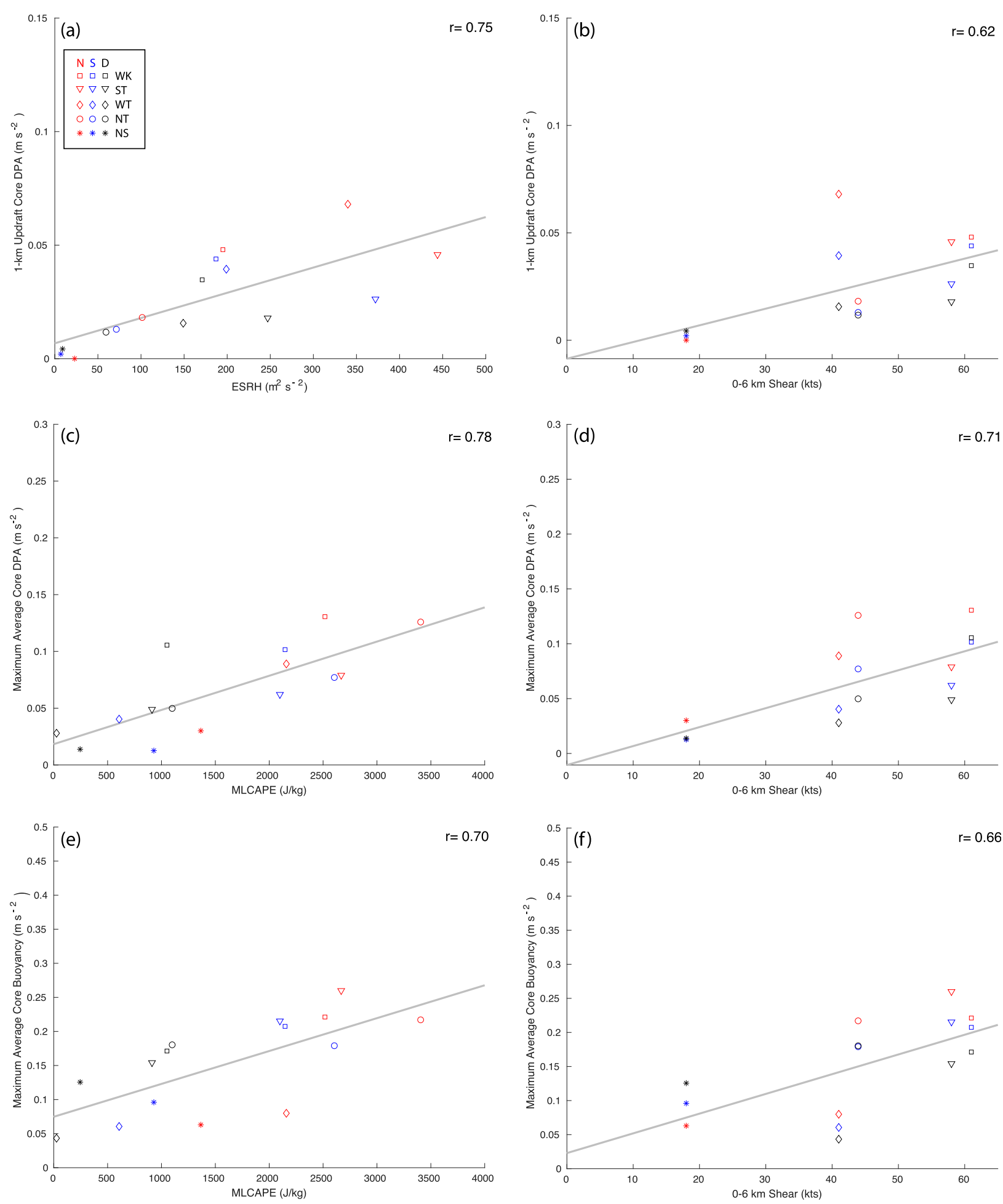

FIG. 14. Scatterplots between selected sounding-derived parameters from each simulation base state and updraft forcing terms.

DPA at $1-\mathrm{km}$ is also positively correlated with $0-1 \mathrm{~km}$ SRH $(r=0.56$; not shown $)$ and $0-3 \mathrm{~km} \mathrm{SRH}(r=0.52$; not shown), but these are notably weaker relationships with than those with ESRH $(r=0.75$; Fig. 14a), perhaps explaining the lack of a significant correlation between fixed-layer SRH values and low-level updraft strength in these simulations. The overall relationship between SRH (regardless of the layer of integration) and low-level DPA 
is consistent with existing studies of supercell low-level updraft forcing in more realistic environments (e.g., Coffer et al. 2017; Parker 2017).

The peak updraft strength in these simulations is strongly correlated with deep-layer shear (Fig. 11b) and moderately correlated with MUCAPE (Fig. 11f), but not significantly correlated with ESRH (Fig. 11d). The strong correlation with deep-layer shear might suggest a prominent role for DPA in the peak updraft forcing; however, recent work has suggested this relationship is largely a function of stronger low-level SR flow leading to wider updrafts with cores that are protected from entrainment-driven dilution and ultimately are able to realize a greater amount of buoyancy (Peters et al. 2019). In our simulations, DPA is considerable throughout the lowest half of the troposphere in the WK, ST, and NT simulations (Fig. 12), but may be offset by negative BPA as suggested by Peters et al. (2019) in at least the WK and NT simulations (Figs. 12a,d) and downward DPA above the midlevel rotation maximum. Buoyancy tends to dominate the updraft forcing within the updraft core above $2 \mathrm{~km}$ for all of the supercell types (Figs. 12a-d). Consistent with the structural differences of the NS updraft (Fig. 5), the NS updraft core displays pockets of weak buoyancy at varying altitudes characteristic of a chain of rising thermals (Fig. 12e). Ultimately, the peak updraft strength in these simulations is strongly correlated with both the maximum updraft core buoyancy and DPA (Figs. 13b,d) at any height below the peak updraft, but values of maximum DPA are often much less than those of buoyancy forcing.

As might be expected, the maximum updraft core buoyancy is positively correlated with both MLCAPE and deep-layer shear (Figs. 14e,f), with the latter relationship potentially a consequence of wider updrafts in highshear environments consistent with a moderate correlation between maximum updraft core buoyancy and both $0-3 \mathrm{~km}$ and effective layer SR flow ( $r=0.59, r=$ 0.63 , respectively). There are positive (though not statistically significant) relationships between deeplayer shear and updraft core area, updraft area and percentage of updraft originating in the EIL, and updraft area and buoyancy (not shown) that are consistent with the results of Peters et al. (2019). Maximum DPA is also well-correlated with deeplayer shear as might be expected (Fig. 14d), but it is also strongly correlated with MLCAPE (Fig. 14c), which is somewhat unexpected. A potential explanation for this relationship is the dependence of DPA on vertical velocity-linear dynamic pressure perturbations are directly dependent on (gradients in) vertical velocity, and nonlinear perturbations may be indirectly dependent on vertical velocity through the stretching term in the vertical vorticity equation. Thus, greater updraft buoyancy forcing resulting from more CAPE and/or wider updrafts in strongly sheared environments may also increase DPA, as suggested by Peters et al. (2020a).

\section{Summary and conclusions}

In this paper, we seek to verify the performance of the Thompson et al. (2007) formulation for the effective inflow layer (EIL) of deep convective storms using a suite of idealized numerical simulations. Analytic soundings and near-storm environments obtained from model analyses of real events were chosen for a range of supercell storm types (significantly tornadic, weakly tornadic, nontornadic) and a nonsupercell severe storm. To modify the EIL base, surface-based temperature inversions of varying depth were added to each base state, resulting in 15 simulations with varying EIL depths, MUP heights, low-level and deep-layer shear, and CAPE. Using an array of passive tracers initialized at varying vertical levels in each simulation, the proportion of air within the resulting updraft cores originating below, within, and above the forecast EIL were determined. Considering the EIL as a forecast of updraft parcel origin, the skill of the EIL was determined for varying updraft core definitions and as a function of near-storm environments. Finally, the role of the near-storm environment on low-level and peak updraft forcing was discussed.

The primary conclusions of our study, in regards to the specific science questions we sought to answer are as follows:

1) How accurate is the EIL as formulated by T07 in predicting the true inflow layer (i.e., the origin height of air participating in the "updraft core") of supercell and nonsupercell updrafts in a variety of realistic environments?

- The EIL tends to perform reasonably well for most storm types. The worst performance was, as hypothesized, for nonsupercells that are characterized by weaker, intermittent, thermal-like updrafts, with significant entrainment of air from above the EIL.

2) How does the EIL performance vary as the definition of "updraft core" is changed?

- As the vertical velocity threshold used to define the updraft core is increased, the probability of the EIL detecting the origin of peak updraft parcels increases as hypothesized, but the chance of the EIL falsely identifying updraft parcels also increases such that overall EIL forecast skill is steady across a range of updraft core definitions. 
- Alternative definitions of the EIL wherein the depth of the EIL is constrained by proximity to the MUP level or SR flow may increase performance for the most stringent definitions of updraft core, but generally result in worse performance for weaker updraft core thresholds.

3) Which environmental parameters best predict EIL performance, and more broadly, low-level and peak updraft forcing and intensity in real environments?

- As hypothesized, EIL performance improves as CAPE, deep-layer shear, and EIL depth increase.

- Low-level updraft strength is most strongly modulated by dynamic forcing, which is strongly correlated with ESRH and, to a lesser extent, deep-layer shear.

- Peak updraft strength is strongly modulated by both buoyancy and dynamic forcing. Maximum updraft core buoyancy and dynamic updraft forcing are strongly related to both CAPE and deep-layer shear, but not ESRH.

The importance of DPA in low-level updraft forcing is largely consistent with prior studies (e.g., Weisman and Klemp 1984; Weisman and Rotunno 2000; Markowski and Richardson 2014; Coffer et al. 2017; Parker 2017). However, there is some indication that larger CAPE may be associated with increased upward buoyancy pressure accelerations below the LFC, thereby also increasing the low-level updraft despite its negative buoyancy. This finding awaits further testing over a larger sample of simulations, including in rotating updrafts embedded in MCSs, where Nielsen and Schumacher (2018) found similar updraft forcing distributions. The role of deep-layer shear in intensifying maximum buoyancy and thereby controlling the peak updraft intensity remains uncertain, though our results are consistent with earlier work by Peters et al. (2019) suggesting that supercell updraft cores are comprised of a much higher fraction of EIL air and less entrainment of air from above the EIL. Moreover, the physical explanation behind the finding that dynamic forcing is related to environmental CAPE is uncertain, but we hypothesize that this is because both nonlinear and linear pressure perturbations are directly or indirectly dependent on updraft strength, such that DPA may increase if updrafts are intensified through buoyancy. We note that these results apply to the mature, relatively steady phase of simulated supercells, but the roles of entrainment and DPA may vary at earlier, developing stages of supercells.

To our knowledge, this is the first study conducting a comprehensive analysis of simulated supercell updraft core origins at all levels in a variety of environments. The results of this paper confirm that the commonly used EIL metric as formulated by Thompson et al. (2007) is largely an accurate reflection of the air ingested by isolated deep convective updrafts over a relatively wide range of realistic thermodynamic and kinematic environments, particularly those associated with elevated supercells. This finding is somewhat at odds with those of Nowotarski et al. (2011) who showed that supercell updrafts could ingest air from near-ground stable layers; however, their study employed a less stringent definition of "updraft" than those tested here. Our results suggest (particularly at weaker updraft core thresholds) that the vast majority of non-EIL air participating in updraft cores aloft is via entrainment, not stable air from below the EIL. Entrainment is particularly notable in nonsupercellular convection. We also note that the commonly used Weisman and Klemp (1982) thermodynamic and kinematic profile results in supercell updrafts with unrealistically small entrainment (at least compared with the real supercell environments simulated herein).

Future work should explore how the EIL performs for multicellular/MCS storm modes, where updraft organization is strongly influenced by outflow and previous studies have shown a layer-lifted approach that integrates outflow interactions with low-level shear over the evolution of individual storms may be more appropriate (Alfaro and Coniglio 2018). Indeed, such an approach may improve inflow approximations of supercellular convection, but testing such methods is beyond the scope of this study. Finally, despite the apparent success of the T07 EIL parameter, our results suggest that the strong dependence of supercell updraft properties on both CAPE and shear warrant continued exploration and efforts to incorporate kinematic variables into parameters that forecast supercell updraft characteristics.

Acknowledgments. We are indebted to George Bryan for his development and continued support of CM1. We thank Rich Thompson and Roger Edwards for providing their proximity sounding dataset used to initialize some of the simulations in this study. J. Peters's and C. Nowotarski's efforts were supported by the National Science Foundation (NSF) Grants AGS-1928666 and AGS-1928319, respectively. Additionally, J. Peters and J. Mulholland were partially supported by NSF Grants AGS-1841674 and Department of Energy Atmospheric System Research Grant DE-SC0000246356. Simulations were performed on Texas A\&M High Performance Research Computing resources. Many sounding-derived parameters and sounding figures were calculated/plotted using SHARPpy (Blumberg et al. 2017). We also thank the editor and reviewers whose constructive comments helped to clarify the manuscript.

Data availability statement. All simulation source code, configuration files, and analysis code are archived 
locally and available upon request to the corresponding author.

\section{REFERENCES}

Alfaro, D. A., 2017: Low-tropospheric shear in the structure of squall lines: Impacts on latent heating under layer-lifting ascent. J. Atmos. Sci., 74, 229-248, https://doi.org/10.1175/JASD-16-0168.1.

- and M. Khairoutdinov, 2015: Thermodynamic constraints on the morphology of a simulated squall line. J. Atmos. Sci., 72, 3116-3137, https://doi.org/10.1175/JAS-D-14-0295.1.

_ , and M. C. Coniglio, 2018: Discrimination of mature and dissipating severe-wind producing mcss with layer-lifting indices. Wea. Forecasting, 33, 3-21, https://doi.org/10.1175/ WAF-D-17-0088.1.

Beebe, R. G., 1958: Tornado proximity soundings. Bull. Amer. Meteor. Soc., 39, 195-201, https://doi.org/10.1175/1520-047739.4.195.

Blumberg, W. G., K. T. Halbert, T. A. Supinie, P. T. Marsh, R. L. Thompson, and J. A. Hart, 2017: Sharppy: An open-source sounding analysis toolkit for the atmospheric sciences. Bull. Amer. Meteor. Soc., 98, 1625-1636, https://doi.org/10.1175/ BAMS-D-15-00309.1.

Brown, M., and C. J. Nowotarski, 2019: The influence of lifting condensation level on low-level outflow and rotation in simulated supercell thunderstorms. J. Atmos. Sci., 76, 1349-1372, https://doi.org/10.1175/JAS-D-18-0216.1.

Bryan, G. H., and J. M. Fritsch, 2002: A benchmark simulation for moist nonhydrostatic numerical models. Mon. Wea. Rev., 130, 2917-2928, https://doi.org/10.1175/1520-0493(2002)130<2917: ABSFMN $>2.0 . \mathrm{CO} ; 2$.

Bunkers, M. J., B. A. Klimowski, R. L. Thompson, and M. L. Weisman, 2000: Predicting supercell motion using a new hodpograph technique. Wea. Forecasting, 15, 61-79, https://doi.org/10.1175/ 1520-0434(2000)015<0061:PSMUAN $>2.0$. CO;2.

,-- - and J. W. Zeitler, 2002: The importance of parcel choice and the measure of vertical wind shear in evaluating the convective environment. Preprints, 21st Conf. on Severe Local Storms, San Antonio, TX, Amer. Meteor. Soc., 379-382.

- D. A. Barber, R. L. Thompson, R. Edwards, and J. Garner, 2014: Choosing a universal mean wind for supercell motion prediction. J. Oper. Meteor., 2, 115-129, https://doi.org/10.15191/ nwajom.2014.0211.

Cintineo, J. L., M. J. Pavolonis, J. M. Sieglaff, and D. T. Lindsey, 2014: An empirical model for assessing the severe weather potential of developing convection. Wea. Forecasting, 29, 639-653, https://doi.org/10.1175/WAF-D-13-00113.1.

Coffer, B. E., M. D. Parker, J. M. L. Dahl, L. J. Wicker, and A. J. Clark, 2017: Volatility of tornadogenesis: An ensemble of simulated nontornadic and tornadic supercells in VORTEX2 envronments. Mon. Wea. Rev., 145, 4605-4625, https://doi.org/ 10.1175/MWR-D-17-0152.1.

,-- R. L. Thompson, B. T. Smith, and R. E. Jewell, 2019: Using near-ground storm relative helicity in supercell tornado forecasting. Wea. Forecasting, 34, 1417-1435, https://doi.org/ 10.1175/WAF-D-19-0115.1.

Davenport, C. E., and M. D. Parker, 2015: Observations of the 9 June 2009 dissipating supercell from VORTEX2. Wea. Forecasting, 30, 368-388, https://doi.org/10.1175/WAF-D-14-00087.1.

Davies, J. M., 2004: Estimations of CIN and LFC associated with tornadic and nontornadic supercells. Wea. Forecasting, 19
714-726, https://doi.org/10.1175/1520-0434(2004)019<0714: EOCALA $>2.0 . \mathrm{CO} ; 2$.

Deardorff, J. W., 1980: Stratocumulus-capped mixed layers derived from a three-dimensional model. Bound.-Layer Meteor., 18, 495-527, https://doi.org/10.1007/BF00119502.

Droegemeier, K. K., S. M. Lazarus, and R. Davies-Jones, 1993: The influence of helicity on numerically simulated convective storms. Mon. Wea. Rev., 121, 2005-2029, https://doi.org/ 10.1175/1520-0493(1993)121<2005:TIOHON>2.0.CO;2.

Fawbush, E. J., and R. C. Miller, 1954: The types of air masses in which North American tornadoes form. Bull. Amer. Meteor. Soc., 35, 154-165, https://doi.org/10.1175/15200477-35.4.154.

Gallo, B. T., A. J. Clark, B. T. Smith, R. L. Thompson, I. Jirak, and S. R. Dembek, 2018: Blended probabilistic tornado forecasts: Combining climatological frequencies with NSSL-WRF ensemble forecasts. Wea. Forecasting, 33, 443-460, https://doi.org/ 10.1175/WAF-D-17-0132.1.

Gerapetritis, H., and J. M. Pelissier, 2004: On the behavior of the critical success index. Eastern Region Technical Attachment, 2004-03, 6 pp.

Hart, J. A., and A. E. Cohen, 2016: The statistical severe convective risk assessment model. Wea. Forecasting, 31, 1697-1714, https:// doi.org/10.1175/WAF-D-16-0004.1.

Kerr, B. W., and G. L. Darkow, 1996: Storm-relative winds and helicity in the tornadic thunderstorm environment. Wea. Forecasting, 11, 489-505, https://doi.org/10.1175/1520-0434(1996) $011<0489$ :SRWAHI $>2.0 . \mathrm{CO} ; 2$.

Klemp, J. B., and R. B. Wilhelmson, 1978: Simulations of right- and left-moving storms produced through storm splitting. J. Atmos. Sci., 35, 1097-1110, https://doi.org/10.1175/1520-0469(1978) 035<1097:SORALM $>2.0 . \mathrm{CO} ; 2$.

Maddox, R. A., 1976: An evaluation of tornado proximity wind and stability data. Mon. Wea. Rev., 104, 133-142, https://doi.org/ 10.1175/1520-0493(1976)104<0133:AEOTPW > 2.0.CO;2.

Mansell, E. R., C. L. Ziegler, and E. C. Bruning, 2010: Simulated electrification of a small thunderstorm with two-moment bulk microphysics. J. Atmos. Sci., 67, 171-194, https://doi.org/ 10.1175/2009JAS2965.1.

Markowski, P., and Y. Richardson, 2010: Mesoscale Meteorology in Midlatitudes. Wiley-Blackwell, $430 \mathrm{pp}$.

— , and —, 2014: The influence of environmental low-level shear and cold pools on tornadogenesis: Insights from idealized simulations. J. Atmos. Sci., 71, 243-275, https://doi.org/ 10.1175/JAS-D-13-0159.1.

Morrison, H., and J. M. Peters, 2018: Theoretical expressions for the ascent rate of moist convective thermals. J. Atmos. Sci., 75, 1699-1719, https://doi.org/10.1175/JAS-D-17-0295.1.

Naylor, J., and M. S. Gilmore, 2012: Convetive initiation in an idealized cloud model using an updraft nudging technique. Mon. Wea. Rev., 140, 3699-3705, https://doi.org/10.1175/ MWR-D-12-00163.1.

Nielsen, E. R., and R. S. Schumacher, 2018: Dynamical insights into extreme short-term precipitation associated with supercells and mesovortices. J. Atmos. Sci., 75, 2983-3009, https://doi.org/10.1175/JAS-D-17-0385.1.

Nowotarski, C. J., and E. A. Jones, 2018: Multivariate self-organizing map approach to classifying supercell tornado environments using near-storm low-level wind and thermodynamic profiles. Wea. Forecasting, 33, 661-670, https://doi.org/10.1175/WAFD-17-0189.1.

, P. M. Markowski, and Y. P. Richardson, 2011: The characteristics of numerically simulated supercell storms situated 
over statically stable boundary layers. Mon. Wea. Rev., 139, 3139-3162, https://doi.org/10.1175/MWR-D-10-05087.1.

Parker, M. D., 2017: How much does "backing aloft" actually impact a supercell? Wea. Forecasting, 32, 1937-1957, https:// doi.org/10.1175/WAF-D-17-0064.1.

Peters, J. M., C. Nowotarski, and H. Morrison, 2019: The role of vertical wind shear in modulating maximum supercell updraft velocities. J. Atmos. Sci., 76, 3169-3189, https://doi.org/10.1175/ JAS-D-19-0096.1.

, C. J. Nowotarski, J. P. Mulholland, and R. L. Thompson, 2020a: The influences of effective inflow layer streamwise vorticity and storm-relative flow on supercell updraft properties. J. Atmos. Sci., https://doi.org/10.1175/JAS-D-19-0355.1, in press.

,$- \ldots$, and G. L. Mullendore, 2020b: Are supercells resistant to entrainment because of their rotation? J. Atmos. Sci., 77, 1475-1495, https://doi.org/10.1175/JAS-D-19-0316.1.

Rasmussen, E. N., and D. O. Blanchard, 1998: A baseline climatology of sounding-derived supercell and tornado forecast parameters. Wea. Forecasting, 13, 1148-1164, https://doi.org/ 10.1175/1520-0434(1998)013<1148:ABCOSD > 2.0.CO;2.

Roebber, P. J., 2009: Visualizing multiple measures of forecast quality. Wea. Forecasting, 24, 601-608, https://doi.org/10.1175/ 2008WAF2222159.1.

Rotunno, R., and J. B. Klemp, 1982: The influence of the shearinduced pressure gradient on thunderstorm motion. Mon. Wea. Rev., 110, 136-151, https://doi.org/10.1175/1520-0493(1982) 110<0136:TIOTSI >2.0.CO;2.

-, and —_, 1985: On the rotation and propagation of simulated supercell thunderstorms. J. Atmos. Sci., 42, 271-292, https://doi.org/10.1175/1520-0469(1985)042<0271:OTRAPO> 2.0.CO;2.

Sherburn, K. D., and M. D. Parker, 2014: Climatology and ingredients of significant severe convection in high-shear, low-CAPE environments. Wea. Forecasting, 29, 854-877, https://doi.org/ 10.1175/WAF-D-13-00041.1.

Showalter, A. K., and J. R. Fulks, 1943: Preliminary report on tornadoes. U.S. Weather Bureau, $162 \mathrm{pp}$.

Smith, B. T., R. L. Thompson, J. S. Grams, C. Broyles, and H. E. Brooks, 2012: Convective modes for significant severe thunderstorms in the contiguous United States. Part I: Storm classification and climatology. Wea. Forecasting, 27, 11141135, https://doi.org/10.1175/WAF-D-11-00115.1.

Thompson, R. L., R. Edwards, J. A. Hart, K. L. Elmore, and P. Markowski, 2003: Close proximity soundings within supercell environments obtained from the Rapid Update Cycle. Wea. Forecasting, 18, 1243-1261, https://doi.org/10.1175/15200434(2003)018<1243: CPSWSE $>2.0$. CO;2.

_ C. M. Mead, and R. Edwards, 2007: Effective storm-relative helicity and bulk shear in supercell thunderstorm environments. Wea. Forecasting, 22, 102-115, https://doi.org/10.1175/ WAF969.1.

Van Den Broeke, M. S., 2016: Polarimetric variability of classic supercell storms as a function of environment. J. Appl. Meteor. Climatol., 55, 1907-1925, https://doi.org/10.1175/JAMC-D-150346.1.

Weisman, M. L., and J. B. Klemp, 1982: The dependence of numerically simulated convective storms on vertical wind shear and buoyancy. Mon. Wea. Rev., 110, 504-520, https://doi.org/ 10.1175/1520-0493(1982)110<0504:TDONSC > 2.0.CO;2.

- , and -1984 : The structure and classification of numerically simulated convective storms in directionally varying wind shears. Mon. Wea. Rev., 112, 2479-2498, https://doi.org/ 10.1175/1520-0493(1984)112<2479:TSACON>2.0.CO;2.

— and R. Rotunno, 2000: The use of vertical wind shear versus helicity in interpreting supercell dynamics. J. Atmos. Sci., 57, 1452-1472, https://doi.org/10.1175/1520-0469(2000)057<1452: TUOVWS $>2.0$.CO;2. 